\title{
Review of solid particle materials for heat transfer fluid and thermal energy storage in solar thermal power plants.
}

\section{Running Head: Solid particle materials in solar thermal power plants}

\author{
Alejandro Calderón ${ }^{1}$, Camila Barreneche ${ }^{1,3}$, Anabel Palacios ${ }^{3}$, Mercè Segarra ${ }^{1}$, Cristina Prieto ${ }^{2} \operatorname{Sanchez}^{2}$, A. Inés Fernández ${ }^{1}$ \\ ${ }^{1}$ Department of Materials Science \& Physical Chemistry, Universitat de Barcelona, Martí i Franqués 1-11, 08028 Barcelona, Spain \\ ${ }^{2}$ Abengoa Solar New Technologies S.A., C/Energía Solar 1, 41014, Sevilla
}

${ }^{3}$ Birmingham Centre for Energy Storage \& School of Chemical Engineering, University of Birmingham, Birmingham B15 2TT, United Kingdom

\begin{abstract}
Current CSP plants that operate at the highest temperature use molten salts as both Heat Transfer Fluid (HTF) and Thermal Energy Storage (TES) medium. Molten salts can reach up to $565{ }^{\circ} \mathrm{C}$ before becoming chemically unstable and highly corrosive. This is one of the higher weakness of the technology. Solid particles have been proposed to overcome current working temperature limits, since the particle media can be stable for temperatures close to $1000{ }^{\circ} \mathrm{C}$. This work presents a review of solid particles span style="font-family:'Times New Roman'">candidates to be used as HTF and TES in CSP plants in open receivers. In addition, the interactions between solid particles with major system components are described in this review e.g. with TES system or heat exchanger. The parameters and properties of solid particles are identified from the material science point of view explaining their nature and the relation to the power plant efficiency and lifetime durability. Finally, future development is proposed; such as material selection according to each specific design, materials characterization or durability test.
\end{abstract}

Keywords: solid particles, CSP, TES, solar tower, granular materials, sensible heat, thermal storage. 


\section{Acronyms}

CSP - Concentrated Solar Power

HEX - Heat Exchanger

HTF - Heat Transfer Fluid

IEA - International Energy Agency

PSD - Particle Size Distribution

SPR - Solid Particle Receiver

TEM - Transmission Electron Microscopy

TES - Thermal Energy Storage

XRD - X-Ray Diffraction 


\section{INDEX}

1. Introduction ---- (04)

2. CSP components: conceptual design --------------------- (06)

2.1 Solid particle receiver

2.2 Storage ---

2.3 Heat Exchanger ----on

2.4 Conveyance ------------ (10)

3. Plant design interaction with particle media --------------o (10)

3.1 Receiver thermal efficiency ----------------------------------------- (12)

3.2 Thermal energy storage capacity ----------------------------------------- (16)

3.3 HEX efficiency --------------------------------------------------------------- (18)

3.4 Erosion evaluation ------------------------------------------------- (21)

3.5Particle durability ------------------- (22)

4. Summary of properties of solid particle materials --- (25)

5. Conclusions and future work ------------------------------------------ (27)

Acknowledgements ---

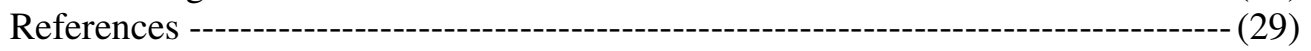




\section{0.}

\section{Introduction}

It has been well established that renewable energy have a major role in energy systems development, energy security and climate change fight [1]. In the last years, electricity capacity additions have grown for renewable technologies such as photovoltaic and wind, reaching greater development than coal or gas utilities [2]. Therefore, the total electricity generation from renewables reached $25 \%$ in 2018 and is expected to grow up to $40 \%$ in 2040 [3]. This can be understood by the current downfall of renewable prices, which is expected to continue with the new International Energy Agency (IEA) expected policies scenario [4] in contrast with the increase of oil prices up to $80 \mathrm{USD} / \mathrm{b}$ arrel in 2018.

Nevertheless, the variable renewable energies growth has some limitations due to lack of flexibility. Solar and wind production (which are the ones that are being more developed) do not match the electricity daily demand. Other dispatchable renewables such as geothermal, hydropower or bioenergy, have resource limitations either because of geographical resource availability or because of conflict with other human activities (such as agriculture and human consumption) [5-7]. Several strategies have been considered for solving this lack of flexibility, being energy storage one of the most promising. Nowadays, one of the most commercially viable energy storage solutions with high capacity is thermal energy storage (TES) system integrated with concentrated solar power (CSP) thermal plants. CSP central tower can achieve high power, high efficiency in the electric generation cycle due to the high operation temperatures, high land efficiency and enough heat storage to overcome solar energy resource variability [8,9]. Power output in CSP thermal plants is important, which is in part influenced by the operating temperature. Achieving high temperature reflects in an increase of heat to electricity conversion efficiency; therefore, increasing temperature is desirable. Central receiver tower concentrator using molten salts reaches temperatures up to $565^{\circ} \mathrm{C}$ - this limit is determined by the molten salt material itself. For higher temperatures molten nitrates salt becomes chemically unstable, becoming highly corrosive and decomposing [10].

Solid particle CSP technology can overcome the molten salts temperature and stability drawbacks, since solid particles are used as TES and heat transfer fluid (HTF) material [11]. The solid particles TES system is expected to have high performance due to the high service temperature, and to the relatively low cost of the material itself [12]. Direct solar absorption receivers, in which particles fall through a beam of concentrated radiation, have the potential to increase temperature of HTF/TES media over $1000{ }^{\circ} \mathrm{C}$ [13]. Therefore, a complete CSP solar tower system that operates over $600{ }^{\circ} \mathrm{C}$ and up to $1000{ }^{\circ} \mathrm{C}$ is feasible, since stable materials are available and thermal self-insulation can minimize thermal losses in the heat storage medium [14]. Finally, media storage system is projected to have cheap maintenance and low material costs [10].

Thus, the main advantages relative to the storage media compared with current commercial molten salts solution can be summarized [13]:

a. Proposed solid particles materials are chemically inert and stable beyond $1100{ }^{\circ} \mathrm{C}$.

b. Particles are capable of storing energy over a greater temperature span compared with other media currently in use; thus, increasing the energy storage density.

c. Materials cost is expected to be relatively low.

Proposed power plant configuration can be appreciated in Figure 1. The sunlight is reflected and concentrated by the solar field heliostats into a central tower. Particles are flowing through the receiver at the top of the tower, capturing the concentrated sunlight. After reaching the desired temperature, the solid particles are moved by the conveyance system to a hot storage tank, in which the material is collected until it's moved into a heat exchanger (HEX) to transfer the high temperature heat to the power generation cycle [32].

Exhausted heat particles are then moved to a (relatively) low temperature storage tank to be stored until they can be moved back to the solar receiver on the top of the tower to harvest solar heat again [12]. This plant distribution is similar to the current commercial molten salts CSP tower system [15]; however, almost all the components of the plant should be specially redesigned for working with solid particles at high temperature. 


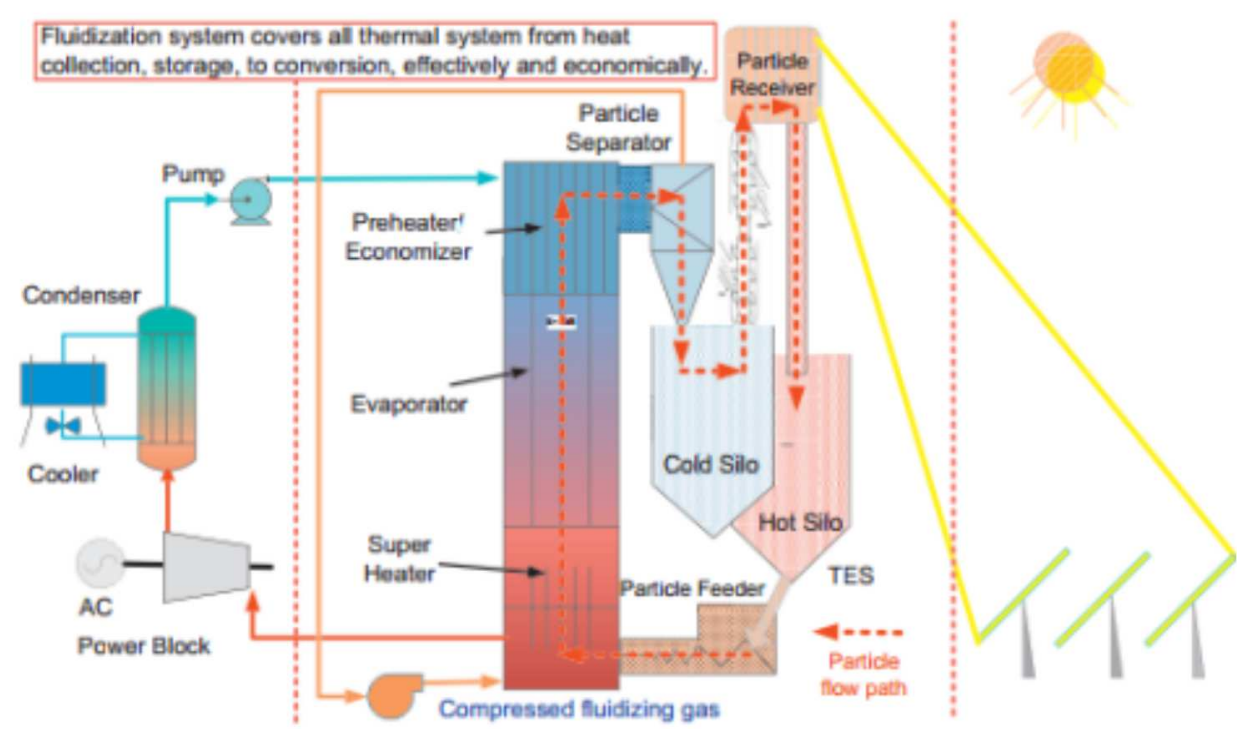

Figure 1. CSP solid particle system with TES and fluidized bed [14].

The main facets involved in solid particle CSP development that have been identified are:

- The receiver design in which particles receive concentrated solar flux and get to the desired high temperature is of great importance. Several designs had been proposed, although some of them are still under development. The most important goal for the receiver is to retain the particles so that they can reach the desired temperature with a high solar absorptance efficiency (either directly or indirectly) [16].

- The Solid Particle TES will allow the power plant to operate at any time and in the most convenient moment (according to the electricity production needs). Reduce heat losses and guarantee silo durability are the main objectives of current research efforts.

- The heat exchanger must provide heat to the power block as quickly as possible and in the shortest possible length. The heat exchanger is expected to be one of the most expensive parts of the system, so making it smaller is highly desirable.

- Particle conveyance considers how to move the solid particles between the receiver, the particle silos and the heat exchanger.

- A solid particle material selection of the must be made to the best meet requirements of each part of the system. In addition, the material compatibility between the particles and the materials of which system parts are built of, must be taken into account.

CSP solid particle technology progress has several challenges. The main concerns that are subject to more study and development are [17]:

a. The complete integration of all concepts. Some functional units are at early stages of study, in contrast to other parts that are much more developed such as solar receiver or heat exchanger. An example of underdeveloped functional unit is the particle conveyance system; even that the energy employed in moving the solid particles through the power plant can seriously affect the energy balance of the plant, and therefore its viability. There is only one reported solar tower developing some integration studies (the National Thermal Test Facility in New Mexico [28,36]); nevertheless, reported studies show that their focus is centered in the receiver concept and heat exchanger design. A full integration study can detect possible conflicts with the working requirements so thathey can be properly solved.

b. Prove the commercial feasibility for each functional part of the plant, including but not limited to the solar receiver, heat storage, heat exchanger, conveyance system and the particle medium.

c. Selecting the optimal materials for solid particles and the system is of big relevance and they must be chosen together, since the interactions between the particles and the components' materials can affect in a great manner the plant and particle medium lifetime and system maintenance cost. Particle media have been suggested and compared in bibliography, but an exhaustive search, selection and evaluation has not been performed. Since there are only a limited number of particle materials that can be used under these high temperature conditions, it is difficult to perform an appropriate materials selection. Selecting materials that are not available reduce the projected viability of the technology. The main desirable characteristics under research for particulate media reported in the literature can be grouped by:

$\checkmark$ Complete optical characterization.

$\checkmark \quad$ Research for new formulations to increase solar absorptance efficiency and absorptance durability over time. 
$\checkmark$ Finding ways to reduce abrasion and attrition caused by/to the particles.

This work presents a review of solid particle CSP technology, its importance, its impact compared with current CSP solutions and their interactions with major components of the plant design not only focused on the receivers or other components because this revisions are available in the literature. Thereby, the key overview is motivated on the particle media point of view, interacting with all the components of the system design.

\section{CSP components: conceptual design \\ 2.1. Solid Particles Receiver}

The most studied functional part of solid particle power plants is the particle receiver, since there are several proposed designs [14,16-27]. Only some of them have been deeply studied, and the most remarkable designs are presented in Figure 2. Solar receivers can be classified according to the way they capture solar heat [32]:

a. Direct receivers, in which the particle media (acting as HTF) directly absorb the solar irradiance. These receiver designs make high solar absorptance to be included among particle media desirable properties.

b. Indirect receivers, that use another material to absorb the solar heat and then exchange it to the particle media.

Once classified in direct or indirect receivers, they are divided according to their working principle. On one hand, the most noticeable direct receivers are the free-falling particle, the obstructed flow, the rotating kiln and the fluidized receivers. On the other hand, the most outstanding indirect receivers are the particle flow with HEX and the fluidized indirect receivers .

It is noticeable that there are no material compatibility studies, for any of the reported receiver designs, between the HTF-TES particle material and the material of which the receivers are going to be built with. Future design studies should include the interactions of plant component with the particle media and their stability in the long term. These interactions have been already observed during the receiver prototype development [30], but even then, has been reported no material selection based on them.

The most groundbreaking designs are for direct receivers' design, in which there is an important need to increase the solar irradiation exposure time to reach the desired high temperatures. To decrease radiative losses and reduce exposure time, the solar absorptance becomes and important property, and a high priority for directly irradiated receiver development [31].

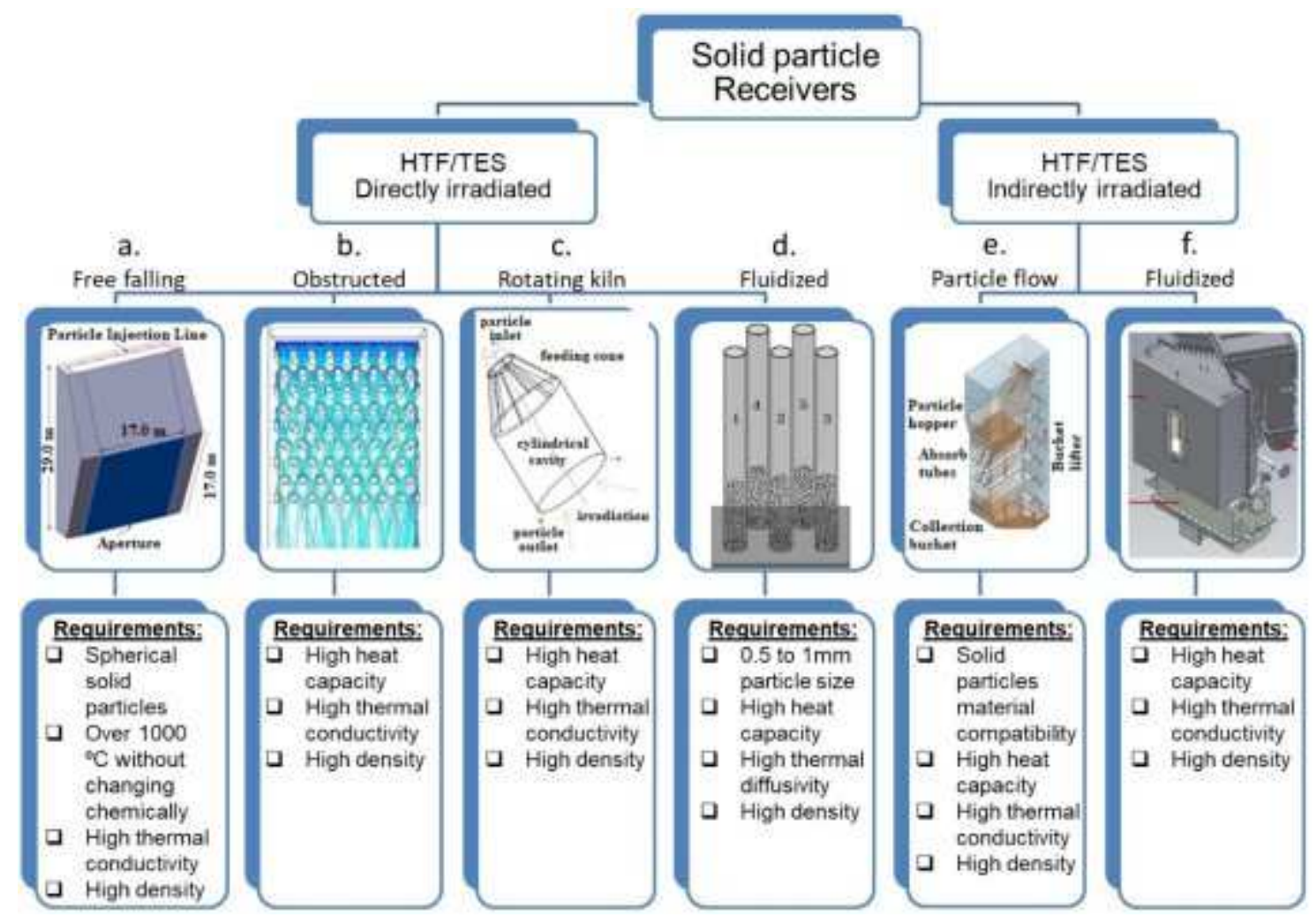

Figure 2. Main parameters and properties for different solid particle solar receivers.

The most relevant receiver designs that are under progress or being designed can be appreciated in Figure 2. Their working principles are explained below:

a. Free falling particle receiver. In this design, the particle media falls through the receiver in a curtain 
shape, while an aperture allows concentrated solar flux entering the receiver and thereby heat the particles. Current efforts are centered in researching ways to increase particle exposure to concentrated sunlight [18]. As mentioned before, it is expected that temperature goes over $1000{ }^{\circ} \mathrm{C}$ without changing the chemical properties or composition of the material, while additionally achieves high solar absorptance efficiency due to direct solar absorption. It is projected that this design will be feasible for $10-100 \mathrm{MW}$ systems [13]. Current studies are centered in [17]:

$\checkmark$ Effects of the receiver aperture size tilt and dimension.

$\checkmark$ Different ways to increase the particles residence time.

$\checkmark$ Develop an air curtain for protecting the receiver aperture.

One option to control residence time is the particle recirculation by making the particles to pass several times through the aperture until they reach the desired temperature [32]. This approach has been modeled and simulations have shown it is effective enough to reach $800{ }^{\circ} \mathrm{C}$; nevertheless, possible particle losses in the aperture must be reduced either by using an air curtain or by any other solution.

b. Obstructed particle flow receiver. Another option to increase particle exposure is by mechanically obstructing the particle media flow. Despite of shortage of material properties considerations (heat capacity, density or thermal conductivity), several options have been proposed [16]:

$\checkmark \quad$ Ceramic porous structures. In this option particle media flow by gravity across porous interconnected structures; thus reducing flow speed and allowing more irradiance exposure. Some tests have already been performed on these structures; results show that there should be a previous material selection that can deal with the deterioration over the porous structure at high temperature.

$\checkmark \quad$ Porcupine structure. Theoretically by placing quills inside the solar receiver, particle media flow can be reduced [17]; however, several testing and material selection must be performed to experimentally assure it.

c. Rotating kiln receiver. In this receiver centrifugal forces are used to slow particle media fall by making them to impact with the kiln walls. Research is focused in maintaining mass flow stability at a large scale and minimizing the energy spent for moving the kiln [18]. Other considerations are related to the particle attrition effect, since the main force that is delaying media flow is due to friction between the kiln walls and the particles.

d. Fluidized direct receiver. Fluidization in the receiver is only possible by controlling the particle flow atmosphere; therefore, to continue working as a direct receiver at high temperature, quartz receivers have been proposed [33]. By controlling particle media flow by fluidization, the solar irradiance over the particles can be increased. A possible drawback that must be studied is the effect of the quartz tube on the solar absorptance of the particle flow. Further studies on different candidate materials show that the particle flow is influenced by particle size, since very small particles decrease the receiver efficiency and very big particles are more difficult to fluidize. Optimal size has been found between 500 a 1000 microns at ambient temperature [33], but it is expected to change at higher temperatures. One improvement compared with other designs is that outside wind has no influence on particle flow.

e. Particle flow integrated with heat exchanger receiver. This indirect receiver considers using an special designed heat exchanger (Figure 2), in which an array of tubes receive the solar irradiance in their interior surface, heating the particles that flow outside the tubes [18]. It is expected that with this design outlet temperature of the particles can reach up to $900^{\circ} \mathrm{C}$. Current studies do not report any material design consideration, not even that they have a central impact on receiver's durability, and on a correct heat exchange and good particle media flow through the receiver.

f. Fluidized indirect receiver. This receiver design considers absorbing the solar heat by a mostly black surface (defined by its weighted solar absorptance in the whole solar spectrum length wave). Then, the heat is exchanged to the particle media flow, controlled by a fluidized bed and forcing the particles upwards, increasing heat transfer by convection with the tube walls [18].

\subsection{Storage}

The original proposed design considers two containers for storing the particle media: a hot and a cold storage. The hot container will hold the particles coming from the solar receiver at high temperature $\left(\sim 80{ }^{\circ} \mathrm{C}\right)$, and will held them until the electricity production is convenient. The cold container will hold the solid particles after they exit the heat exchanger, storing them at low temperature $\left(\sim 350{ }^{\circ} \mathrm{C}\right)$ before sending them back to the solar receiver to be heated up again $[34,35]$. The cold tank will store the particle media until the solar resource is available for solar heat harvesting.

Current research is focused on two main approaches [10]:

a. Interaction between storage elements and other plant components.

b. Cost reduction of storage containers based on understanding heat transfer processes. 
The study of possible thermal losses has been found remarkable, and should be studied for several charge/discharge cycling. Efficient insulation TES systems are important due to the high temperature of the stored particle media [28].

\subsection{Heat exchanger}

There are several options available for discharging heat from the particle media into the power generation block, such as using fluidized bed or packed bed heat exchangers. The most studied is the fluidized bed, which uses two phase gas-solid HTF flow [12,14,36]. The solid phase corresponds to the particle media while the gas phase corresponds to pressurized air. This design has also been studied for latent and thermochemical storage heat discharge, besides the sensible heat used in particle media [14]. In the past, HEXs have been proven to be useful for integration of solid particles with fluids such as compressed air and steam; nevertheless, no studies on their implementation at high temperatures are found, or on the optimization of working conditions, fitting flow rates such as those used in solid particles CSP, or considering shape and size variations of particles during plant lifetime [22].

Other studies can be found related to gravity driven packed bed heat exchangers that evaluate the heat transfer coefficient under different flows and temperatures. They state that when increasing the flow rate the heat transfer increases as well [37]; but also, when temperature is over $600{ }^{\circ} \mathrm{C}$ heat transfer changes from a linear heat transfer coefficient to a faster one [38]. Another proposed HEX solution has been made by Albrecht et al [29] by using a particle $\mathrm{sCO}_{2}$ heat exchanger. Predictive numerical models have been performed for moving packed-bed exchangers, finding performance relations with particle size, operating temperature, and flow speed. These models are expected to allow heat exchange simulations after being it experimentally validated.

\subsection{Conveyance}

Particle transport is considered to be of special importance due to the energy spent in moving the solids. By now, only the particle media lift to the solar receiver has been reported; while other conveyance elements for the rest of media transportation have not been described. For fluidized bed, there are some testing on erosion and corrosion protections, such as weld overlay and plasma spray coatings which have been useful for ceramic materials [12]. A formal material selection must be performed, since the used particle media determines the interaction and durability of the possible materials used for the conveyance system caused by their interaction.

Energy spent in particle lifting is a main concern when considering the whole system viability. Almost all the proposal lifting technologies come from mining industry, such as mine hoists, bucket elevators, pocket elevators, screw conveyors, olds elevators, pneumatic conveyors, conveyor belts, cleated conveyor belts, metallic belted conveyors, En-masse's elevators, bucket wheels, linear induction motor powered elevators, and electromagnetic field conveyors. Nevertheless, only olds elevators, conventional bucket lifts, and pocket elevators have been tested at temperatures above $800{ }^{\circ} \mathrm{C}$ and had been considered for efficiency calculations [28].

\section{Plant components interaction with particle media}

The overall concept in solid particles as HTF and TES for CSP tower was explained in previous sections. The suitable selection of the particle media is one of the most important considerations to evaluate the viability of the overall plant. In order to reach an optimal performance several aspects must be considered, which must be congruent with the desired particle media properties and other design parameters such as low price and high temperature stability [34]. Natural materials or byproducts should be considered due to their low price, while composite materials that can enhance some desired behaviors, must be with caution considered due to their possible high price.

A material selection must be performed to choose the best material available for particulate media [39]. Thus, the main properties and funciontal parameters must be identified before starting any material selection process. Some efforts for indentifying these parameters have been made before [40]; specific heat, thermal shock, thermal conductivity, particle size and shape, and attrition effect have been considered. Nevertheless, further efforts to identify all properties and their interaction on the different parts of the solid particle solar plant have been not found on literature. There are specific requirements for the solid particle material according to functional parts of the plant or to desirable behavior of the solids. In Table 1, suggested properties and funciontal parameters are presented according to the mentioned criteria. 
Table 1. Desired properties and functional parameters for solid particles for CSP.

\begin{tabular}{|c|c|c|c|c|}
\hline & Range & Desired value & Unit & Reference \\
\hline \multicolumn{5}{|c|}{ Receiver thermal efficiency } \\
\hline Absorptivity & $0.55-0.93$ & High & $\%$ & {$[28]$} \\
\hline Emissivity & $0.72-0.88$ & Low & $\%$ & [28] \\
\hline Particle size & $200-1000$ & ATD* & $\mu \mathrm{m}$ & [26] \\
\hline Sphericity & 0.9 & High & parts per unit & {$[23,26,41]$} \\
\hline Roundness & 0.9 & Low & parts per unit & [42] \\
\hline \multicolumn{5}{|c|}{ HEX efficiency } \\
\hline Particle size & $160-504$ & Low & $\mu \mathrm{m}$ & [43] \\
\hline Thermal conductivity & $0.5-2$ & High & $\mathrm{W} / \mathrm{m} \mathrm{K}$ & [14] \\
\hline \multicolumn{5}{|c|}{ Thermal energy storage capacity } \\
\hline Density & $2.56-5.37$ & High & $\mathrm{g} / \mathrm{cm}^{3}$ & [44] \\
\hline Specific heat & $621.75-923.36$ & High & $\mathrm{J} / \mathrm{kg} \mathrm{K}$ & [44] \\
\hline \multicolumn{5}{|c|}{ Agglomeration } \\
\hline Sphericity & & High & & {$[45]$} \\
\hline Size uniformity & & High & & [43] \\
\hline Melting point & 1135 & High & ${ }^{\circ} \mathrm{C}$ & [46] \\
\hline Particle size & $150-200$ & High & $\mu \mathrm{m}$ & [46] \\
\hline Absorptance & & Low & & [17] \\
\hline \multicolumn{5}{|c|}{ Sintering } \\
\hline Melting point & $>1000$ & High & ${ }^{\circ} \mathrm{C}$ & {$[47]$} \\
\hline Sphericity & 0.9 & High & parts per unit & {$[23,26,41]$} \\
\hline Roundness & 0.9 & High & parts per unit & [42] \\
\hline $\begin{array}{l}\text { Size uniformity (mass } \\
\text { median diameter) }\end{array}$ & $\begin{array}{c}\text { As much as } \\
0.26\end{array}$ & High & parts per unit & [47] \\
\hline Particle size & $200-1000$ & High & $\mu \mathrm{m}$ & {$[26]$} \\
\hline Agglomeration & & Low & & {$[45]$} \\
\hline Sintering heat * & $>1000$ & High & ${ }^{\circ} \mathrm{C}$ & [31] \\
\hline \multicolumn{5}{|c|}{ Durability } \\
\hline Sand erosion & $0.0001-0.1$ & Low & $\%$ & [34] \\
\hline $\begin{array}{l}\text { Thermal shock } \\
\text { degradation }\end{array}$ & & Low & & {$[28]$} \\
\hline $\begin{array}{l}\text { Mechanical shock } \\
\text { degradation }\end{array}$ & $0.004-0.01$ & Low & $\%$ & {$[28]$} \\
\hline \multicolumn{5}{|c|}{ Economic factors } \\
\hline Price & $0.01-17$ & Low & USD/kg & {$[17,48]$} \\
\hline Sand erosion & & Low & & \\
\hline Durability & & High & & \\
\hline
\end{tabular}

*ATD: according to the design.

Different approaches for determining the most important functional parameters have been made; sometimes there are focused on a general view of the plant, while in other cases they are analyzed from the perspective of a single functional unit or constraint (HEX, receiver, storage, durability, etc.). In the following sections, different perspectives have been grouped according to the functional unit or constraint, without differentiating the plant design, in order to consider all parameters and properties. Future work should consider these elements for specific material selection according to each type of plant design.

\subsection{Receiver thermal efficiency}

Some traditional high temperature ceramic materials available in the particle sizes of interest for falling particle 
receiver development have been considered for evaluation studies. Some of these materials are: alumina, silica, silicon carbide, zirconia, as well as sintered materials such as those used as proppants [16].

For direct receivers, the particle media serve as solar absorber, HTF and TES material. Therefore, optical radiative properties of the particles have a critical role in the receiver overall efficiency. Thermal losses can increase if solar absorptance of the particle media is too low and/or if the emissivity is too high because within this scenario the time of residence of the particles to achieve the desired temperature must be increased, and this fact will increment the energy losses.

Solar absorptance has shown to be a more important parameter to maximize compared to getting down emissivity; meaning that a high emissivity material can be considered as good if solar absorptance is high, while a low solar absorptance material cannot be considered even if its emissivity is low [28].

The fraction of radiation absorbed on material surface is called the absorptance or absorptivity [57]. Absorptance is determined by the amount of light absorbed by a material surface compared with a black body [70], and it depends on the source from which the surface absorbs radiation [71]. Solar absorptance is weighted according to the amount of light received from sunlight into the Earth. Figure 3 shows the variation of solar irradiance according to each wavelength starting in the ultraviolet, including the visible spectra and finishing in the infrareds.

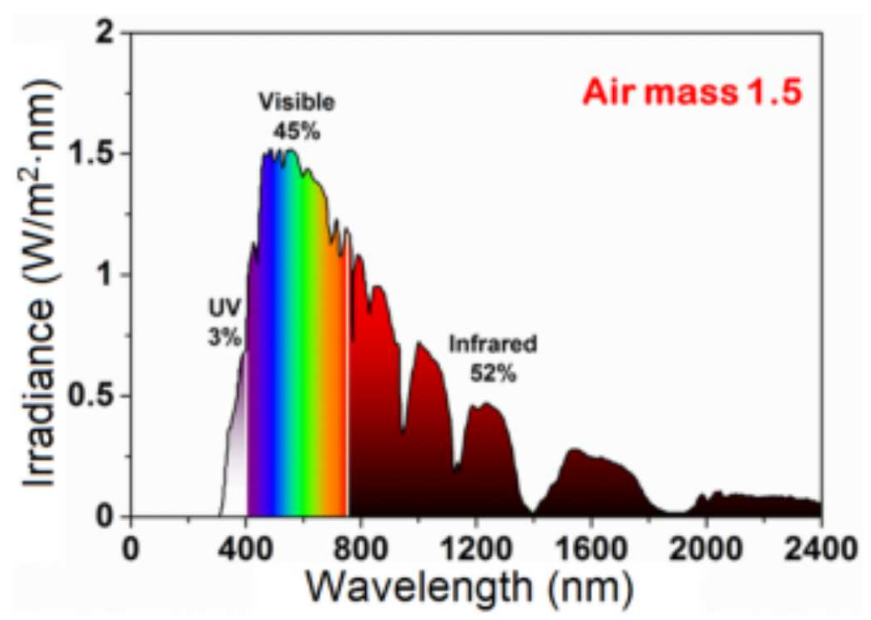

Figure 3. AM 1.5 solar irradiance on Earth [49].

The ratio of the total radiating power of a real surface to that of a black surface at the same temperature is called the emittance of the surface (for a perfectly plane surface, the emissivity) [42]. Emittance is determined by physical properties and temperature of the surface [50]; therefore, the higher the temperature, the higher the emittance. In CSP TES and HTF materials, emittance is undesired through the whole plant, except for the heat exchanger (even that it is not de main heat transfer mechanism) [51].

Thermal heat transfer by thermal radiation is almost immediate, and it depends mainly on the concentrating factor, absorptance, emittance, temperature distribution and scattering medium [52].

Concentrated solar radiation harvesting study is not a new subject, since it has been exploited for solar thermal power (thermal energy), solar thermochemistry (chemical energy), and concentrated solar photovoltaics (electric energy) [53].

Solar concentration ratio is the very first parameter to consider in CSP systems. Desired concentrating ratio defines the configuration and dimension of the solar field. Solar field constitutes one of the main expenses of any kind of CSP technology. Ideal solar irradiance is about $1 \mathrm{~kW} / \mathrm{m}^{2}$ without any concentration. For reaching high temperature the concentrating ratio must be increased in order to limit the radiation losses in the solar receiver [53].

Thermal radiation heat transfer is determined by electromagnetic waves emitted by matter, which changes the molecular energy levels of the receptor material [52]; this is significantly different when compared with thermal conduction or convection which require a material medium to transfer the heat (which is ruled by Fourier's law). Solar thermal radiation used for obtaining solar absorptance include wavelengths between $10^{-7} \mathrm{~m}$ and $10^{-3} \mathrm{~m}$ (ultraviolet, visible, and infrared), since they are determined by solar irradiance spectrum. In contrast, emissivity relies only in the infrared wavelengths [52]. Since the heat transfer net balance goes from the hotter material to the colder (because of the temperature dependence), the heat transfer relative to the absorptance 
comes from the Sun, while the heat transferred relative to the emittance is transferred from the particle media to its surroundings.

Heat transfer by conduction and convection has a linear relation to temperature, but in radiation heat transfer, there is a proportional relation to at least the fourth power with the temperature. As a consequence, radiative heat transfer becomes much more important when increasing temperature, overriding the conduction and convection heat transfer [52]. Therefore, there are high potential losses due to radiation rejection and radiation emitted by particle media compared to those from the insulation of the solar receiver.

When dealing with small particles, such as solid particles for CSP, the interaction between the electromagnetic waves and the particles can change when compared to a continuous solid. When dealing with a particle cloud, radiation may be transmitted, reflected or absorbed (as well as in homogeneous solids); but the directions in which the particles scatter the electromagnetic waves depend of particle's shape, size, material, and space between the particles [52]. For idal particles, the shape is assumed spherical or cylindrical when making analysis. Therefore, the solar irradiance electromagnetic waves (or photons) will be absorbed or scattered by diffraction, reflection or refraction [54]. Theoretically, the properties that can be measured on solid materials are extinction coefficient, absorption coefficient, and scattered intensity. For some authors, the easiest property to measure is the extinction coefficient.

In Table 2 several candidate materials for particle media are presented with their solar absorptance at ambient temperatures and thermal emissivity calculated to $700{ }^{\circ} \mathrm{C}$. These materials include sintered bauxite proppants (CarboHSP ${ }^{\circledR}$, Accucast ${ }^{\circledR}$ and CabroProp ${ }^{\circledR}$ ), fracking sand, and Pyromark ${ }^{\circledR}$ paint (used as reference). The reported measurements were made with a Surface Optics Corporation 410 Solar reflectometer. Absorptance for some of the proppants is relatively high; nevertheless, these results are for particles without any exposure to high temperatures. In Table 2, selective absorber efficiency, $\eta$, is defined as:

$$
\eta=\left(\alpha Q-\varepsilon \sigma T^{4}\right) / Q
$$

where ${ }^{\alpha}$ is the solar absortance, $\mathrm{Q}$ is the irradiance in the receiver $\left(\mathrm{W} / \mathrm{m}^{2}\right),{ }^{\varepsilon}$ is the thermal emissivity, ${ }^{\sigma}$ is the Stefan-Boltzmann constant $\left(5.67 \times 10^{-8} \mathrm{~W} / \mathrm{m}^{2} \cdot \mathrm{K}^{4}\right)$, and $\mathrm{T}$ is the surface temperature $(\mathrm{K})$. For current suggested particle materials, $\mathrm{Q}$ is assumed to be $6 \times 10^{5} \mathrm{~W} / \mathrm{m}^{2}$ and $\mathrm{T}$ is assumed to be $700{ }^{\circ} \mathrm{C}(973 \mathrm{~K})$ on the reported analysis.

Table 2. Measured solar absorptance and thermal emissivity of candidate particles and Piromark 2500® paint used as reference [28].

\begin{tabular}{|c|c|c|c|c|}
\hline Material Name & Type & $\begin{array}{c}\text { Solar weighted } \\
\text { absorptivity } \\
\text { (parts per unit) }\end{array}$ & $\begin{array}{c}\text { Thermal } \\
\text { emissivity } \\
\text { (parts per unit) }\end{array}$ & $\begin{array}{c}\text { Selective } \\
\text { Absorber } \\
\text { Efficiency } \\
\text { (parts per unit) }\end{array}$ \\
\hline \multirow{2}{*}{$\begin{array}{c}\text { Carbo HSP } \\
\text { CarboProp40/70 }\end{array}$} & Sintered Bauxite & 0.934 & 0.843 & 0.864 \\
\hline & Sintered Bauxite & 0.929 & 0.803 & 0.862 \\
\hline CarboProp30/60® & Sintered Bauxite & 0.894 & 0.752 & 0.831 \\
\hline AccucastID50® & Sintered Bauxite & 0.906 & 0.754 & 0.843 \\
\hline AccucastID70® & Sintered Bauxite & 0.909 & 0.789 & 0.843 \\
\hline Fracking Sand & Silica & 0.55 & 0.715 & 0.490 \\
\hline Pyromark2500® & High-Temperature Paint & 0.97 & 0.88 & 0.897 \\
\hline
\end{tabular}

As mentioned above, solar energy received on an individual particle within a particle curtain is absorbed or scattered. Therefore, if the curtain density is high enough, it is expected that a big part of the scattered energy will be absorbed by surrounding particles. This phenomenon allows current solar absorptance and thermal emissivity measurements to use particle media packed bed model, since the incident wavelengths can be absorbed as well as the scattered reflections. Previously commented ceramic proppants have shown high sphericity and roundness; they are ideal for its use in the Solid Particle Receiver (SPR) since scattered radiation can be easily absorbed with current particles shape.

The main design purpose of proppants is hardness, since it is expected to hold hydraulic cracks open in order to allow oil flow out the impermeable rocks. Proposed proppants are made from sintered bauxite, which is noncorrosive, resistant to sintering by pressure, and cheap due to the large production economic scale. Several 
different proppant formulations have been evaluated in terms of their absorptance with a mean solar absorptance over $90 \%$. Nevertheless, as-received proppants are not designed for high temperatures and are not stable under oxidation conditions [31]. Oxidation changes color of the proppants when reaching temperatures over $700{ }^{\circ} \mathrm{C}$; this will be discussed in section 3.5, which is focused on particle durability.

Manufacture process, as well as raw materials used for proppants, are the cause of high absorptance. The fabrication steps are not usually published. One example is that the humidity in the air at during the particle sinterization affects the color of propanant (due to the change in oxygen partial pressure). Raw feedstock is processed into powder, which is pelletized producing green particles. These particles are sintered at temperatures over $1400{ }^{\circ} \mathrm{C}$ in a rotary kiln in a non-oxidizing controlled atmosphere [31]. The main proppants considered by different research groups are the ones from CARBO Ceramics, including CARBO HSP ${ }^{\circledR}$, CARBO Accucast ${ }^{\circledR}$ and CARBO Prop ${ }^{\circledR}$ formulas. In Table 3 CARBO HSP ${ }^{\circledR}$ main properties are presented, while in Table 4 chemical composition, size, specific heat capacity and measured solar absorptance are presented for other CARBO Ceramics products, as well as Norton Masterbeads ${ }^{\circledR}$, which is no longer produced but was earlier studied.

Table 3. CARBO HSP ${ }^{\circledR}$ particle properties [23].

\begin{tabular}{lc}
\hline \multicolumn{1}{c}{ Property } & Value \\
\hline Density $\left(\mathbf{k g} / \mathbf{m}^{\mathbf{3}}\right)$ & 3560 \\
Median diameter $(\boldsymbol{\mu m})$ & 697 \\
Estimated thermal conductivity $(\mathrm{W} / \mathrm{m} \cdot \mathrm{K})$ & 2.0 \\
Estimated specific heat $(\mathrm{J} / \mathrm{kg} \cdot \mathrm{K})$ & $-1.12 \mathrm{e}-3 \mathrm{~T}^{2}+2.07 \mathrm{~T}+264$ \\
Estimated emissivity & 0.8 \\
Sphericity & 0.9 \\
\hline
\end{tabular}

Table 4. Summary of physical properties of commercially available proppants [31].

\begin{tabular}{lcccc}
\hline $\begin{array}{c}\text { Composition/Physical } \\
\text { property }\end{array}$ & CARBOHSP ${ }^{\circledR}$ & CARBOCCUCAST ${ }^{\circledR}$ & CARBOPROP ${ }^{\circledR}$ & $\begin{array}{c}\text { Norton } \\
\text { Masterbeads® }\end{array}$ \\
\hline $\mathrm{AlO}_{3}(\mathrm{wt} \%)$ & 83 & 75 & 72 & 86 \\
$\mathrm{SiO}_{2}(\mathrm{wt} \%)$ & 5 & 11 & 13 & 3 \\
$\mathrm{TiO}_{2}(\mathrm{wt} \%)$ & 3.5 & 3 & 4 & 4 \\
$\mathrm{Fe}_{2} \mathrm{O}_{3}(\mathrm{wt} \%)$ & 7 & 9 & 10 & 7 \\
$\mathrm{Others}(\mathrm{wt} \%)_{\text {Mean diameter }[\mu \mathrm{m}]}^{3}$ & 1.5 & 2 & 1 & - \\
Heat capacity $\left[\mathrm{J} / \mathrm{kg}^{3} \cdot \mathrm{k}\right.$ & $1275\left(700^{\circ} \mathrm{C}\right)$ & $\left.1175(70)^{\circ} \mathrm{C}\right)$ & $1175\left(700{ }^{\circ} \mathrm{C}\right)$ & -600 \\
Bulk density $\left[\mathrm{g} \cdot \mathrm{cm}^{3}\right]$ & 2.0 & 2.0 & 1.88 & - \\
Weighted solar & 93 & 91 & 89 & 94 \\
absorptance $(\%)$ & & & & 94 \\
\hline
\end{tabular}

These proposed particles are engineered materials for high pressure applications; nevertheless, they exhibit high absorptance and durability while remaining useful for temperatures over $1000^{\circ} \mathrm{C}$ [35].

For falling particle receiver different particle size media have been tested between 200 and 1000 microns. It has been found that smaller particles result on a bigger receiver solar aperture if the same operation conditions remain. The study suggests that particle media selection must consider manufacturing issues, since too small particles can lead to mass flow loose through the concentrated sunlight aperture [26].

For direct fluidized bed receivers a two-phase suspension with small particles is considered, which flows vertically through the absorbing tubes to harvest solar thermal energy. For previous reported testing the particle media used was silicon carbide. This material was chosen due to its high sintering temperature, high specific heat capacity, availability and intermediate cost (depending on the literature reference) $[11,12]$. Silicon carbide media average diameter also allowed good fluidization quality with low velocities, which yield to parasitic electric charges reduction.

\subsection{Thermal energy storage capacity}

For thermal storage, the thermal capacity of the storage media should be as large as possible (equation 2); Table 5 show values for iron ores and some slags. However, a high real density will penalize the fluidization, since materials with high density require more energy to get to the minimum fluidization speed, $\mathrm{u}_{\mathrm{mf}}$. This minimum 
speed can be compensated with a smaller particle size in order to keep the design velocity constant no matter the material used. On the other hand, as has been commented on section 2.1, too small particles can be negative for fluidization as well. Finally, smaller size will have a negative effect on sintering, as will be explained on section 2.6.

$\varepsilon=\rho c_{p}$

Table 5. Potential storage media [36].

\begin{tabular}{|c|c|c|c|c|c|c|}
\hline & $\begin{array}{c}\mathrm{C}_{\mathbf{p m}} \\
{[\mathrm{J} / \mathrm{kgK}]}\end{array}$ & $\begin{array}{l}\rho \\
{\left[t / m^{3}\right]}\end{array}$ & $\begin{array}{c}\mathcal{E}=\rho \mathbf{C p} \\
{\left[\mathrm{J} / \mathrm{cm}^{3} \cdot \mathbf{K}\right]}\end{array}$ & $\begin{array}{r}\mathbf{U}_{\mathrm{mf}} \\
{[\mathrm{mm} / \mathrm{s}]} \\
50 \mu \mathrm{m}\end{array}$ & $\begin{array}{r}\mathbf{U}_{\mathbf{m f}} \\
{[\mathrm{mm} / \mathrm{s}]} \\
100 \mu \mathrm{m}\end{array}$ & $\begin{array}{c}\mathrm{U}_{\mathrm{mf}} \\
{[\mathrm{mm} / \mathrm{s}]} \\
150 \mu \mathrm{m}\end{array}$ \\
\hline Quartz $\mathrm{SiO}_{2}$ & 742.13 & 2.65 & 1.97 & 2.5 & 8.5 & 17.2 \\
\hline \multicolumn{7}{|c|}{ Feldspar } \\
\hline Albite $\mathrm{NaAlSi}_{3} \mathrm{O}_{8}$ & 782.16 & 2.62 & 2.05 & 2.4 & 8.5 & 17.0 \\
\hline Microcline $\mathrm{KAlSi}_{3} \mathrm{O}_{8}$ & 727.19 & 2.56 & 1.86 & 2.4 & 8.3 & 16.6 \\
\hline Anorthite $\mathrm{CaAl}_{2} \mathrm{Si}_{2} \mathrm{O}_{8}$ & 759.85 & 2.76 & 2.10 & 2.6 & 8.9 & 17.9 \\
\hline \multicolumn{7}{|c|}{ Mica } \\
\hline $\begin{array}{l}\text { Muscovite } \mathrm{KAl}_{2}\left(\mathrm{AlSi}_{3} \mathrm{O}_{18}\right) \\
(\mathrm{F}, \mathrm{OH})_{2}\end{array}$ & 818.71 & 2.83 & 2.32 & 2.6 & 9.1 & 18.4 \\
\hline $\begin{array}{l}\text { Fluorphlogopite } \\
\mathrm{KMg}_{2} \mathrm{AlSi}_{3} \mathrm{O}_{10} \mathrm{~F}_{2}\end{array}$ & 812.83 & 2.88 & 2.34 & 2.7 & 9.2 & 18.7 \\
\hline \multicolumn{7}{|c|}{ Pyroxene } \\
\hline Jadeite $\mathrm{NaAl}\left(\mathrm{SiO}_{3}\right)_{2}$ & 791.29 & 3.35 & 2.65 & 3.1 & 10.6 & 21.8 \\
\hline Diopside $\mathrm{CaMg}\left(\mathrm{SiO}_{3}\right)_{2}$ & 768.96 & 3.28 & 2.52 & 3.0 & 10.4 & 21.3 \\
\hline$\alpha$-Spodumene $\alpha$-LiAlSi ${ }_{2} \mathrm{O}_{6}$ & 853.89 & 3.19 & 2.72 & 2.9 & 10.2 & 20.7 \\
\hline$\beta$-Spodumene $\beta$-LiAlSi ${ }_{2} \mathrm{O}_{6}$ & 874.85 & 2.38 & 2.08 & 2.2 & 7.7 & 15.5 \\
\hline \multicolumn{7}{|c|}{ Iron Ores } \\
\hline Hematite $\mathrm{Fe}_{2} \mathrm{O}_{3}$ & 650.31 & 5.28 & 3.43 & 4.7 & 16.3 & 34.2 \\
\hline Magnetite $\mathrm{Fe}_{3} \mathrm{O}_{4}$ & 651.25 & 5.20 & 3.39 & 4.6 & 16.0 & 33.8 \\
\hline \multicolumn{7}{|c|}{ Slags } \\
\hline Aluminium oxide, $\mathrm{Al}_{2} \mathrm{O}_{3}$ & 761.05 & 3.97 & 3.02 & 3.6 & 12.5 & 25.8 \\
\hline Magnesium oxide, $\mathrm{MgO}$ & 923.36 & 3.58 & 3.31 & 3.3 & 11.3 & 23.3 \\
\hline Manganese oxide, $\mathrm{MnO}$ & 621.75 & 5.37 & 3.34 & 4.7 & 16.5 & 34.8 \\
\hline Titanium dioxide, $\mathrm{TiO}_{2}$ & 687.73 & 4.23 & 2.91 & 3.8 & 13.2 & 27.5 \\
\hline
\end{tabular}

Specific heat capacity is the quantity of heat needed to raise the temperature one degree Celsius per gram of sample at constant pressure [55]. This property is inherent to each material, and is different according to the physic state of the material and for each temperature.

Specific heat is of great matter due to its relation to the storage energy density. When combining it with bulk density, it has a major role in determining the size of the heat storage container and to the charge/discharge time. For ceramic materials (which are the most commonly suggested materials for solid particle CSP) the specific heat is between 0.75 and $1 \mathrm{~J} / \mathrm{g} \cdot \mathrm{K}[45]$. For example, specific heat for granite is $0.79 \mathrm{~J} / \mathrm{g} \cdot \mathrm{K}$ at $25^{\circ} \mathrm{C}$.

Real density of particles is the mass of the material related to its volume, excluding porosity and empty space between particles. On the other hand, bulk density (also known as apparent density) includes the space between particles and the pores (open or isolated) of the material itself. Because of this, bulk density for packed solid particles is closely related to the pack arrangement of the particles [56]. Density variation can be appreciated in Figure 4, depending on the way the particles are packed. 


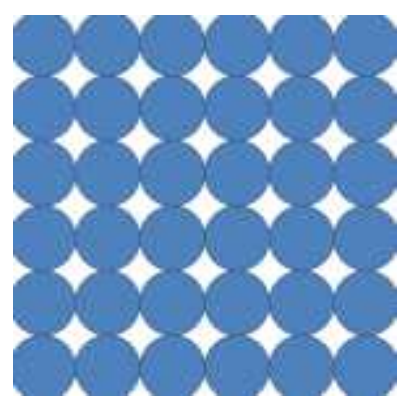

(a)

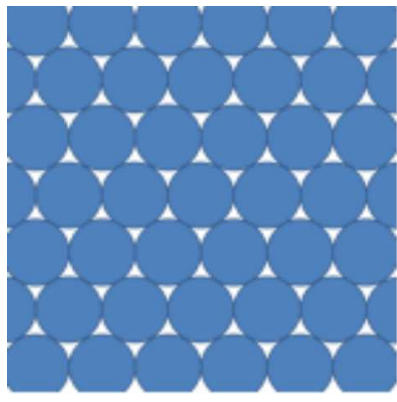

(b)

Figure 4. Loosely packed (a) and tightly packed (b) particles.

It can be expected that in particle storage a bulk density gradient can be formed, having tightly packed particles in the bottom of the storage, since material pressure from above help to pack the particles below them [57]. This phenomenon must be considered for avoiding sintering since area contact and pressure increase can enhance sintering. Density values are highly important to be taken into account that will define the energy density of the material and the final total heat storage capacity of the system.

The first suggested particle media is silica sand, since it is a natural product, abundant, available all over the earth crust, it's an inert material, and with a good thermal energy storage capacity. It is mostly made of $\mathrm{SiO}_{2}$ and has been used as TES material for other applications [34,58]. Also, silica sand can be easily presented in a large variety of size distribution and, since it is used for fluidization technology, the correlations used in fluidization engineering are valid [36]. Thereby, Diago et al. [59] suggested silica sand as storage medium although the calcium content of the sand must be controlled since the highest the calcium content, the highest the sand agglomeration in the receiver. An alternate option to overcome agglomeration is to use two type of sand, a commercial silica and a foundry sand made from olivine [34]. The originality of this system is that it uses a combined sand conveyor and a HEX called Sand Shifter. Test results of this system are shown in Table 6. From these results the Sand Shifter system costs are estimated in Table 7.

Table 6. Preliminary heat transfer results [34].

\begin{tabular}{lc}
\hline \multicolumn{1}{c}{ Material } & Heat transfer $\left(\mathbf{W} / \mathbf{m}^{\mathbf{2}} \mathbf{K}\right)$ \\
\hline Silica sand over flat plate & $310-400$ \\
Silica sand over finned plate & $212-405$ \\
Olivine sand over flat plate & $550-925$ \\
Olivine sand over finned plate & $376-635$ \\
\hline
\end{tabular}

Table 7. Sand shifter TES system costs [34]

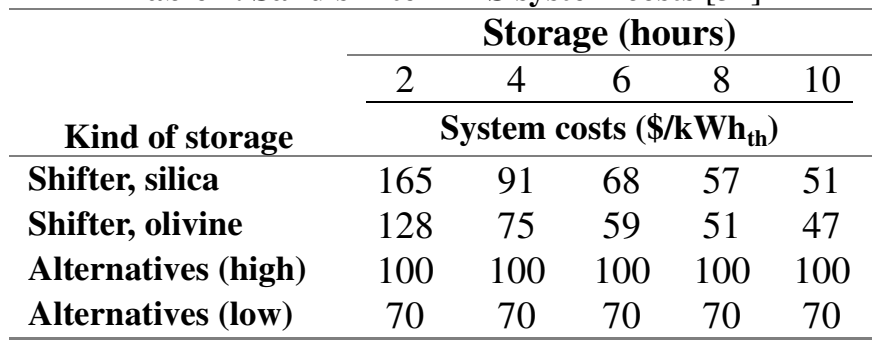

\subsection{HEX efficiency}

From the HEX point of view, the parameters to consider include their thermal and mechanical stability, material properties, performance of fluidization and flowability (either for fluidized or packed bed), understanding of the heat transfer and heat exchange design, and material handling knowledge. Also, other factors that should be considered are grouped to be included into the selection process [14]:

a. Factors that influence in the fluidized bed system performance, stability, and energy density. Some of the properties reported that affect these factors are composition, softening temperature, density, specific heat capacity, mean particle size, particle size distribution, and void fraction.

b. For packed bed solutions, a high packing density with a high heat capacity is desirable. In addition, high resistance to agglomeration and sintering is important for durability considerations. Resistance to mechanical and thermal shock is important due to the high mechanical and thermal stresses that the particles receive in the heat exchanger [16].

c. Factors related to particle size. Although the particle size has little influence in the storage, it has a big influence in the heat transfer, either for indirect receivers or for the heat exchanger performance. It is 
expected that smaller particle sizes have a better heat exchange performance for most of the cases; however, there is a limit for fluidized bed heat exchange in order to get the higher heat transfer coefficient.

d. Another factor is related to the fluidized bed boiler, which separates gas/solid phases. This element is influenced by the particle size and density relation in order to get the best possible performance.

Thermal conductivity and specific surface area are related to the HEX size and therefore, to its building cost. The thermal conductivity represents the relation between heat transferred and the temperature difference given a certain material thickness. This can be appreciated in the one dimensional equation:

$Q=k \cdot \frac{\Delta T}{L}$

where $\mathrm{L}$ is the thickness, $\mathrm{Q}$ is the thermal energy, $\mathrm{k}$ is the thermal conductivity value and $\Delta \mathrm{T}$ is the temperature difference between the beginning and end of the conducting material [60].

As shown in Figure 5, the molecules in two bodies at different temperatures have different average kinetic energies. Collisions occurring at the contact surface tend to transfer energy from high-temperature regions to low-temperature regions. Thermal conductivity is related to the heat exchange rate for charging (at solar receiver) and discharging (at heat exchanger), and it is considered one of the main properties that are not related directly to the particle durability [14].

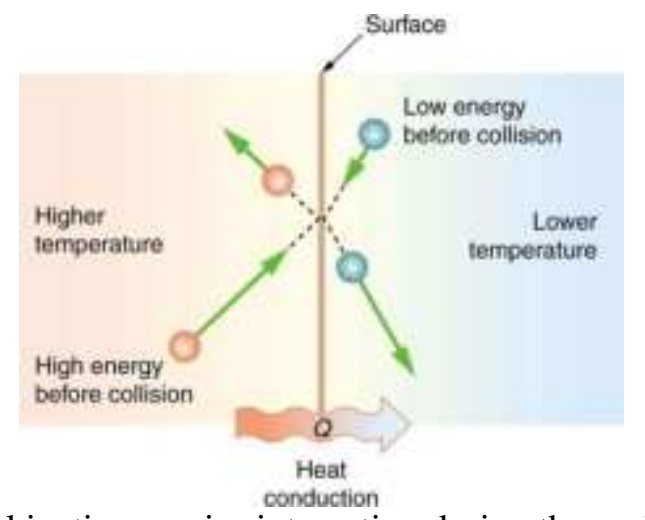

Figure 5. Molecule kinetic energies interaction during thermal conductivity [61].

The relation between the surface area of a solid and the mass contained in it is defined as the specific surface (surface area divided by the mass), including the exposed pores in the material [79]. Particles with high specific surface can favor a quick discharge in a convective heat transfer (such as in fluidized bed heat exchangers). Specific surface for some concrete particle materials are presented in Figure 6.

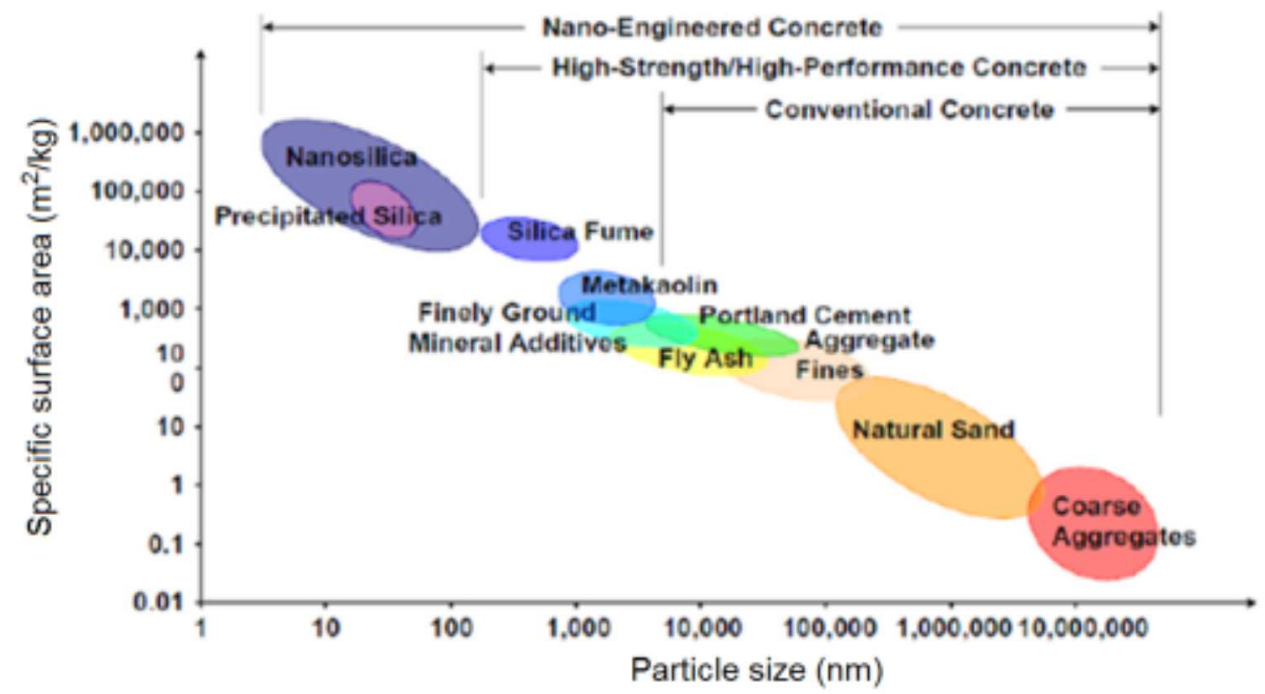

Figure 6. Specific surface area for different concrete materials [62].

In practice, it is not common to find particle materials that are monodisperse, even that it is desirable for solid particle CSP. The reality is that knowing the mean size is not enough to make an enhanced analysis of the material; therefore, a complete distribution analysis is desirable. Particle Size Distribution (PSD) can be analyzed by volume or by number; each one of both interpretations has its advantages [63]. For example, determining PSD by number can easily detect smaller particles, which cannot be seen in a PSD by volume. An example of both ways to analyze PSD results is shown on Figure 7 for the same sample. 
Knowing the size distribution in the particle material is a very useful way to measure and predict solid particle material stability. PSD is an important indicator of quality and performance, and values like mean, median and mode are used to determine the kind of distribution being measured [64]. An increase in bigger particles and a decrease in the smaller ones can indicate sintering, while a decrease in bigger particles and increase in smaller ones can indicate particle rupture. Also, removing particles can help to avoid possible sintering, since smaller particles increase packing and contact area between the particles [45].

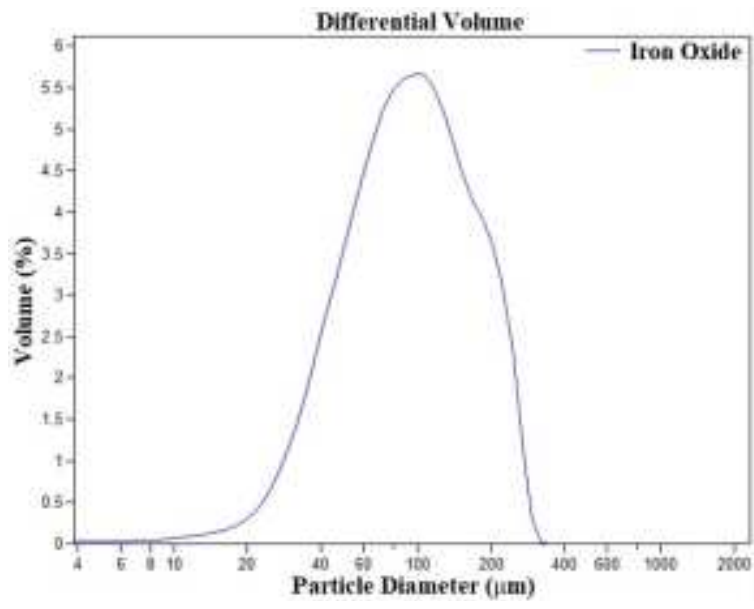

(a)

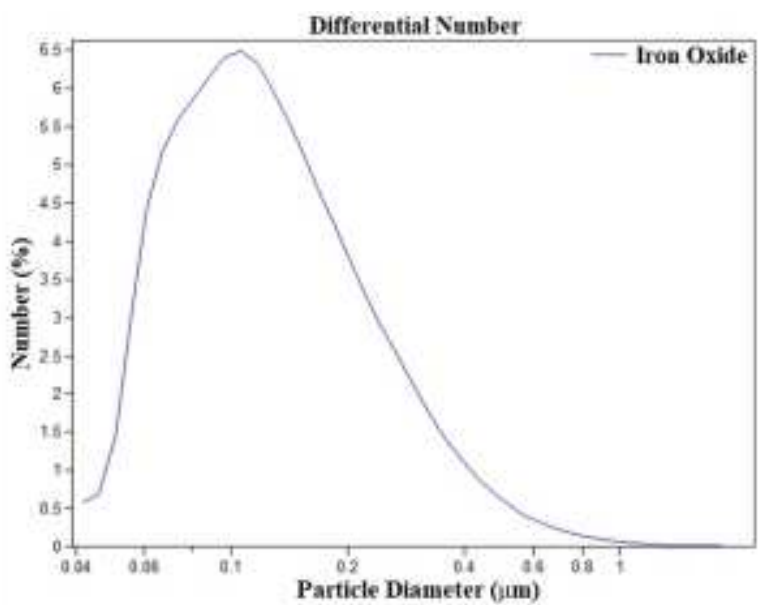

(b)

Figure 7. Example of PSD by volume (a) and by number (b) for the same sample.

Some materials have been proposed considering them from the heat exchanger point of view, such as silica sand and fly ash. Since fly ash has $\mathrm{Al}_{2} \mathrm{O}_{3}$ in its composition, it has a high thermal conductivity and stability when compared to silica sand even that both are low cost and have good thermochemical stability [12]. Some of the proposed materials properties can be appreciated in Table 8.

Table 8. Solid-particle materials considered to be used on the heat exchanger [12]

\begin{tabular}{|c|c|c|c|c|}
\hline Material & Composition & Cost & Benefits & Concern \\
\hline Silica sand & $\mathrm{SiO}_{2}$ & Low & Stable & Low thermal conductivity \\
\hline Quartz sand & $\mathrm{SiO}_{2}$ & Medium & Purity & Quartz inversion \\
\hline Alumina powder & $\mathrm{Al}_{2} \mathrm{O}_{3}$ & High & Stable & High cost \\
\hline Fly ash & $\mathrm{SiO}_{2}+\mathrm{Al}_{2} \mathrm{O}_{3}$ & No/low & Experienced & $\begin{array}{c}\text { Containing Corrosive } \\
\text { minerals }\end{array}$ \\
\hline Silicon carbide & $\mathrm{SiC}$ & High & $\begin{array}{l}\text { High thermal } \\
\text { conductivity }\end{array}$ & Hard surfaces \\
\hline Graphite pebble & $\mathrm{C}$ & High & High specific heat & Oxidization, easy attrition \\
\hline
\end{tabular}

Other material challenges for particle media from HEX perspective suggested by Zhiwei Ge et al. [65] include: high energy density, great durability, large temperature range, improved thermal properties, and low cost. Also, Geldart et al. [44] suggested a classification founded on material's performance based on particle mean diameter and on material's real density. They concluded that if the particles are too small they cannot be easily fluidized. A diagram was created to classify the particles in A-aeratabel, B-sand like, C-cohesive and D-spoutable; as consequence, optimal materials to be fluidized should be type A and type B granular materials. Other observation was made by Schwaiger et al. who concluded that a higher heat capacity has more benefits than higher real density [36].

Some artificial or sintered materials have been considered, such as crushed fire bricks or powder made of heat resistant coatings. These materials are easy to fluidize, have high specific heat capacity and high density. Main composition for both of them includes aluminum oxide $\left(\mathrm{Al}_{2} \mathrm{O}_{3}\right)(\sim 2 / 3)$ and magnesium oxide $(\mathrm{MgO})(\sim 1 / 3)$. Actually, it has been proposed to try to minimize particle density so that air needed for fluidization can be reduced as well as the parasitic energy consumption. The main disadvantage for artificial or sintered materials is that the price is expected to be higher compared to natural o byproduct materials.

\subsection{Erosion evaluation}

When moving particle media there are two phenomena that create particle attrition, the first is the inter-particle collision, and the second is the interaction between the particle media and the walls (either of the conveyance, HEX or SPR systems) [69]. The greater attrition effect is expected on the HEX fins and tubing, but can be 
important on fluidized bed receivers and some of the particle elevators previously considered.

Roundness and sphericity define the factor shape of particles, and it is an important factor (together with material hardness) that determines the erosion damage to the system. Roundness define how smooth are the edges of the particle, while sphericity defines the relation to its three orthogonal axes [66]. Mathematically, the sphericity can be defined as:

Sphericity $=\sqrt[3]{\frac{\text { Particle volume }}{\text { volume of a sphere that completely surrounds the particle }}}$

While roundness can be calculated by:

Roundness $=\frac{\text { Average radius of corners and edges }}{\text { Radius of maximum inscribed circle }}$

A table guide was proposed by Krumbein et al. in 1956 [67], and showed in Figure 8, makes more easy to identify the sphericity and the roundness based on the particle appearance.

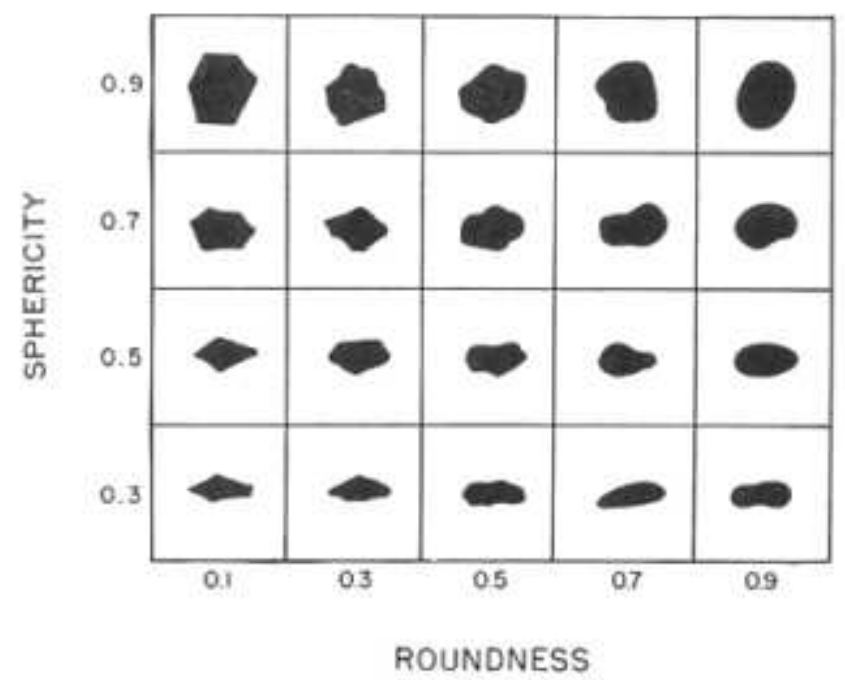

Figure 8. Sphericity and roundness classification [67].

Some studies have made analysis by mass measurement at periodic attrition intervals using silica sand as particle media. The results indicate that copper tubes with aluminum fins experience wear in short time, while copper tubes with steel fins took more than ten times longer to experience the same wear. Early results showed that, by using silica sand, a steel HEX tube can lose only $1 \%$ of its mass. When using olivine for evaluating the erosion on the previous described scenarios, no significant wear was found [52]. This suggests that there is a dependence on the combination of materials used for the system and the particle media; hardness (that has a variation with temperature) and shape can have critical influence when evaluating wear.

Erosion effect on the falling particle receiver has been evaluated within the collection hopper and other structures. Loss of less than $0.004 \%$ mass was reached by particles velocities below $7 \mathrm{~m} / \mathrm{s}$. For velocities of more than $10 \mathrm{~m} / \mathrm{s}$ loss exceeded $0.01 \%$. The attrition was expected to be high for the first cycles, as the surface of the particles may not be too smooth. The particle media used for the evaluation of the erosion on the falling SPR was proppants, which have high roundness and sphericity, but high hardness [51].

A suggested alternative for reducing wear on falling receiver is to buffer the particle impact by using some of the previously studied porous structures. Nevertheless, it has been appointed that for these structures the attrition effect must be mitigated when considering the ceramic material to be used. Also, curved structures made of resistant ceramics have been suggested for slowly decelerate the particles fall [51]. From the particle media point of view, the fracture resistance tests show that there is a critical impact velocity related to the compressive stress and fracture toughness of the particles. This impact fracture is more relevant for particles with reduced sphericity and roundness [42].

\subsection{Particle durability}

When evaluating particle media durability for CSP, we must consider that the high temperature conditions will remain years while residing on the thermal energy storage tanks. Some studies suggest that there should be a regenerating process for the particle media; nevertheless, the complexity and energy required has not been 
evaluated as far [31]. Another effect on durability is the one caused by the stress generated by quick temperature variation and continuous heat charge/discharge cycles. This effect must be further studied since there are no reported works on this matter.

Since proppant materials proposed are primarily composed by sintered bauxite, the variation between them from the chemical composition point of view depends on the ratio of alumina to silica and to the minor oxides present. It is expected that a material used for direct solar irradiance harvest, should have at least $85 \%$ of solar absorptance. When considering particle media durability, long term heat effect must be considered, since a minor variation in composition can lead to considerable solar absorptance variation. Solar absorptance characterization has been performed to the previously mentioned proppants after up to 200 hours heat treatment at $700{ }^{\circ} \mathrm{C}$ and $1000{ }^{\circ} \mathrm{C}$. Absorptance and emissivity variation can be appreciated on Figure 9 for several proppants. At $1000{ }^{\circ} \mathrm{C}, \mathrm{CARBO} \mathrm{HSP} \circledast$ changes considerably after only 24 hours, dropping from $93 \%$ to $91 \%$, while emissivity decays from $85 \%$ to $84 \%$. In contrast, at $700{ }^{\circ} \mathrm{C}$ the change takes place considerably slower [48].

At long term, the absorptance can be reduced below $85 \%$ critical point at $1000{ }^{\circ} \mathrm{C}$, while for $700{ }^{\circ} \mathrm{C}$ remains above $92 \%$. Composition analysis by X-Ray Diffraction (XRD) showed evidence of small chemical transformations in the bauxite crystalline phases, containing oxides of aluminum, silicon, titanium and iron. These results suggest that there are changes on the oxidation state without a related phase change [51].
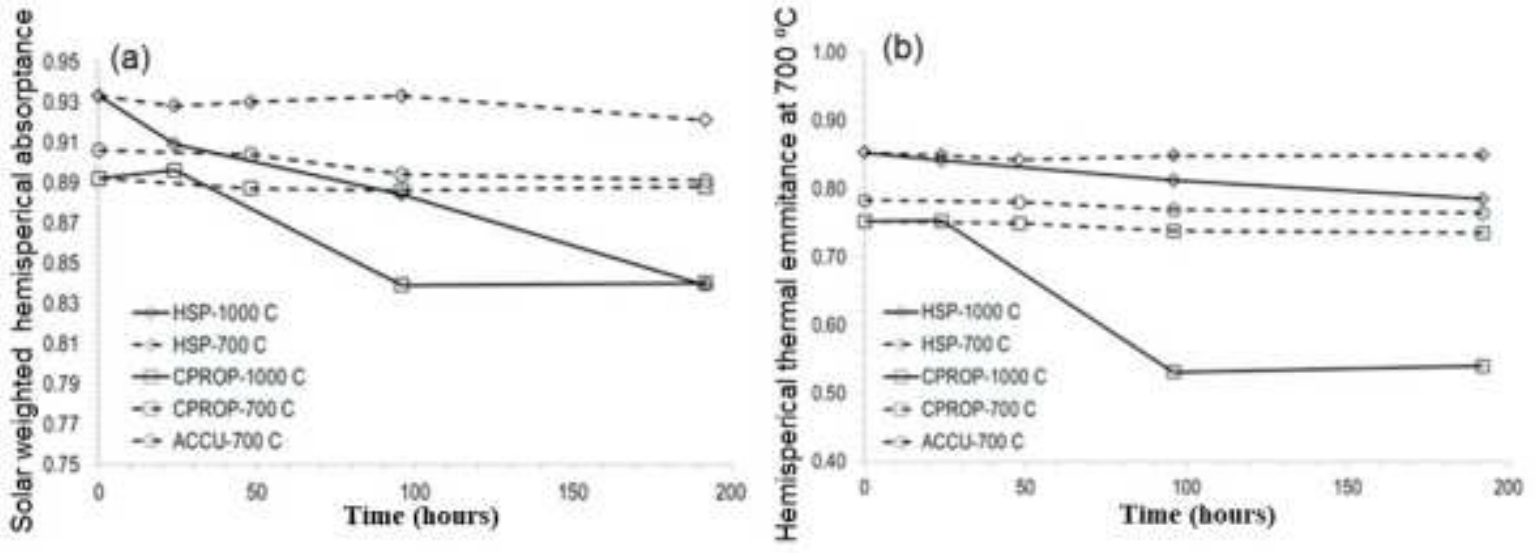

(a) Solar weighted hemispherical absorptivity for three proppant candidates as a function of heating duration; (b) hemispherical thermal emissivity as a function of heating duration [31].

When making the thermal treatments under a chemically reducting atmosphere $\left(5 \% \mathrm{H}_{2}\right.$ in either $\mathrm{N}_{2}$ or $\left.\mathrm{Ar}\right)$ the solar absorptance increased for either as-received particles or previously degraded particles [31]. Absorptance variation can be appreciated in Figure 10a and color change on the particles in Figure $10 \mathrm{~b}$.
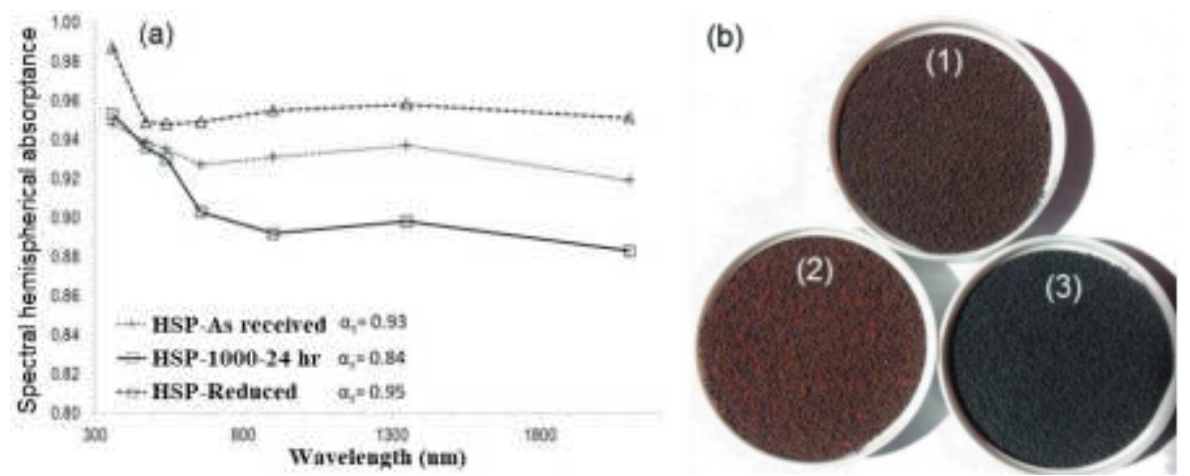

Figure 10. (a) The spectral hemispherical absorptivity of chemically reduced CARBOHSP® $(700 \circ \mathrm{C}$ for 20 hours) compared to as received and heat treated samples; (b) images of CARBOHSP $®$ in the (1) as received condition, (2) after heating in air at $1000{ }^{\circ} \mathrm{C}$ for 24 hours, and (3) after chemical reduction [31].

Sintering happens when material small particles (or powder) transform into a solid body without melting the original material, no matter if it is composed of crystalline o amorphous structures. This phenomenon can seriously affect particle shape and size distribution; therefore, it affects the particle media durability. Sintering is enhanced by high temperatures, high pressure and high contact surface between the particles and the amount of time these conditions are applied over the particle media [62].

Agglomeration happens when there is a radical rearrangement of particles; it is more noticeable in metals and 
solid ceramics. Agglomeration is considered an early stage of sintering, since it is one of the conditions that favor sintering. Several experiments and simulations have shown that strength, shape, mean size and size distribution affect the evolution of the microstructure on agglomeration process and then on sintering process [61]. A particle size distribution with a big standard deviation causes the smaller particles increase the contact areas, as well as they are more vulnerable to get sintered into a bigger particle. For solid particle CSP the main objective is avoiding agglomeration and sintering, and the most vulnerable moment for particles to agglomerate or sintering is at the lower part of the hot tank storage.

For characterizing the degree of agglomeration of one sub-section of particle media there is a parameter called "variance", for which the effects of particle size distribution and inter-particle viscosity are analyzed [61].

Agglomeration research has found that alumina, silica and zircon have the best behavior when being used between $1000{ }^{\circ} \mathrm{C}$ to $1200{ }^{\circ} \mathrm{C}$. There has also been found that there is a relationship with solar absorptance, since low solar absorptance indicates that the particle media can behave better on agglomeration issues. Therefore, further studies on material selection and research has to be performed to find a good balance for these contradictory conditions.

Determining agglomeration by experimental or theoretical research has been found difficult since agglomeration occurs with smaller particles, broader particle size distribution, higher temperature, smaller tangential viscosity or smaller initial volume fraction [42]; therefore, even having different initial particle size distributions it can still lead to different agglomerations.

Melting point of a solid is the phase change from solid to liquid. For solid particle materials for CSP it is very important because this change should be avoided during materials lifetime.

For ceramic materials, low melting points (even if it is over the service temperature) can indicate possible agglomeration and sintering problems. Sintering is enhanced with pressure, temperature and/or surface area increase. For ceramic materials, sintering temperature is close to $70 \%$ of the melting point temperature [45]. Sintering process can be appreciated in Figure 12 (concept model) and Figure 11 (TEM image).

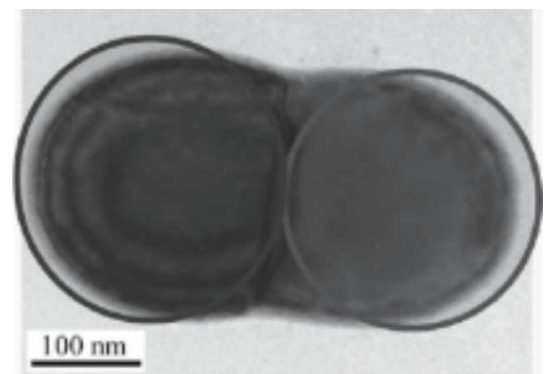

Figure 11. Si particles partially sintered [45].

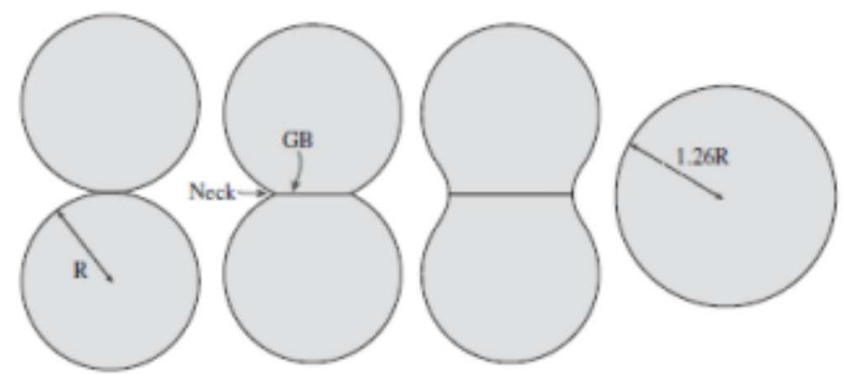

Figure 12. 2D 4 step sintering model [45].

Other solid-solid phase change must be considered and studied for the service temperature range, since they can result in a density change that can modify the particles physically, causing rupture or increasing the specific surface (increasing the possibility for chemical reactivity).

\section{Summary of properties of solid particle materials}

Table 9 and Table 10 summarize the solid particles properties which are available in the literature. Therefore, absorptance, thermal conductivity, specific heat, density, and price are listed in this table in order to compare the proper candidates available to be used as solid particles for CSP plants. 
Table 9. Summary of solid particle optical properties, cost and density to be used for CSP where, $\alpha$-absorptance, $\varepsilon$-emissivity, $\rho$ - bulk density.

\begin{tabular}{|c|c|c|c|c|c|c|}
\hline Material & Composition & $\alpha$ & $\varepsilon$ & $\begin{array}{c}\text { Cost } \\
(\text { eur/kg) }\end{array}$ & $\rho\left(\mathrm{g} / \mathrm{cm}^{3}\right)$ & Reference \\
\hline Silica Sand & $\begin{array}{c}92 \%-\mathrm{SiO}_{2} \\
06 \%-\mathrm{Al}_{2} \mathrm{O}_{3} \\
<1 \%-\mathrm{Fe}_{2} \mathrm{O}_{3} \\
<1 \%-\mathrm{K}_{2} \mathrm{O} \\
<1 \%-\mathrm{TiO}_{2}\end{array}$ & $0.44-0.66$ & $0.59-0.9$ & $0.35-0.52$ & $2.1-2.65$ & {$[36,68-73]$} \\
\hline Hematite & $\begin{array}{c}98 \%-\mathrm{Fe}_{2} \mathrm{O}_{3} \\
01 \%-\mathrm{FeO} \\
<1 \%-\mathrm{Mn}_{2} \mathrm{O}_{3}\end{array}$ & 0.85 & 0.56 & N/A & 5.28 & {$[36,74,75]$} \\
\hline $\begin{array}{l}\text { Silicon } \\
\text { Carbide }\end{array}$ & $\mathrm{SiC}$ & N/A & $0.83-0.96$ & $12.3-17.5$ & $3-3.2$ & {$[68,71]$} \\
\hline AccucastID® & $\begin{array}{c}75 \%-\mathrm{Al}_{2} \mathrm{O}_{3} \\
11 \%-\mathrm{SiO}_{2} \\
03 \%-\mathrm{TiO}_{2} \\
09 \%-\mathrm{Fe}_{2} \mathrm{O}_{3}\end{array}$ & 0.906 & 0.754 & N/A & N/A & {$[28,31,72]$} \\
\hline CarboHSP® & $\begin{array}{c}83 \%-\mathrm{Al}_{2} \mathrm{O}_{3} \\
05 \%-\mathrm{SiO}_{2} \\
04 \%-\mathrm{TiO}_{2} \\
07 \%-\mathrm{Fe}_{2} \mathrm{O}_{3}\end{array}$ & 0.934 & 0.843 & N/A & 3.56 & {$[23,28,31]$} \\
\hline Alumina & $\mathrm{Al}_{2} \mathrm{O}_{3}$ & $0.1-0.25$ & $0.3-0.5$ & $28.1-35.1$ & $3.94-3.96$ & {$[36,71,76]$} \\
\hline Zirconia & $\begin{array}{l}95 \%-\mathrm{ZrO}_{2} \\
04 \%-\mathrm{MgO}\end{array}$ & N/A & $0.42-0.62$ & $15.8-22.8$ & $6.03-6.16$ & {$[71,77]$} \\
\hline CarboProp® & $\begin{array}{c}72 \%-\mathrm{Al}_{2} \mathrm{O}_{3} \\
13 \%-\mathrm{SiO}_{2} \\
04 \%-\mathrm{TiO}_{2} \\
10 \%-\mathrm{Fe}_{2} \mathrm{O}_{3}\end{array}$ & $0.89-0.93$ & $0.75-0.80$ & N/A & 1.56 & {$[28,31,78]$} \\
\hline $\begin{array}{l}\text { Titanium } \\
\text { Dioxide }\end{array}$ & $99 \%-\mathrm{TiO}_{2}$ & $0.4-0.7$ & $0.5-0.8$ & $21-31.6$ & $3.97-4.05$ & {$[71,76]$} \\
\hline $\begin{array}{l}\text { Magnesium } \\
\text { oxide }\end{array}$ & $\mathrm{MgO}$ & N/A & $0.2-0.5$ & $29.8-43.8$ & $3.54-3.58$ & {$[36,71,76,79]$} \\
\hline Manganosite & $\begin{array}{c}98 \%-\mathrm{MnO} \\
1.7 \%-\mathrm{MgO} \\
<1 \% \mathrm{Fe}_{2} \mathrm{O}_{3}+\mathrm{FeO}\end{array}$ & N/A & N/A & N/A & 5.43 & {$[75,80-82]$} \\
\hline Olivine & $\begin{array}{c}42 \%-\mathrm{MgO} \\
39 \%-\mathrm{SiO}_{2} \\
19 \%-\mathrm{FeO}\end{array}$ & N/A & N/A & $35-43$ & $2.8-3.37$ & {$[71,83]$} \\
\hline Fly ash & $\begin{array}{c}88 \%-\mathrm{SiO}_{2} \\
05 \%-\mathrm{CaO} \\
02 \%-\mathrm{Al}_{2} \mathrm{O}_{3} \\
<1 \%-\mathrm{Fe}_{2} \mathrm{O}_{3}\end{array}$ & N/A & N/A & $0.03-0.14$ & $1.83-2.2$ & [71] \\
\hline Graphite & $\mathrm{C}$ & 0.84 & 0.98 & $9.47-14.4$ & $1.61-1.67$ & {$[69,71,74]$} \\
\hline Basalt & $\begin{array}{c}48-59 \%-\mathrm{SiO}_{2} \\
15-18 \%-\mathrm{Al}_{2} \mathrm{O}_{3} \\
07-12 \%-\mathrm{Fe}_{2} \mathrm{O}_{3} \\
06-09 \%-\mathrm{CaO} \\
04-05 \%-\mathrm{Na} \mathrm{O} \\
03-05 \%-\mathrm{MgO}\end{array}$ & N/A & 0.72 & $2.01-2.22$ & $2.5-2.89$ & {$[68,71,84]$} \\
\hline
\end{tabular}




\begin{tabular}{|c|c|c|c|c|c|}
\hline \multicolumn{6}{|c|}{$\begin{array}{l}\text { Table 10. Summary of solid particle thermal properties to be used for CSP } \\
\text { where, } k \text { - thermal conductivity, } C_{p}-\text { specific heat capacity. }\end{array}$} \\
\hline Material & $\begin{array}{l}\text { Melt point } \\
\left({ }^{\circ} \mathbf{C}\right)\end{array}$ & $\begin{array}{l}\text { Service temp } \\
\quad\left({ }^{\circ} \mathbf{C}\right)\end{array}$ & $\begin{array}{c}\mathbf{k} \\
\left(\mathbf{W} / \mathbf{m}-{ }^{-} \mathbf{C}\right)\end{array}$ & $\underset{\left(\mathbf{J} / \mathbf{k g}-{ }^{\circ} \mathbf{C}\right)}{\mathbf{C}_{\mathbf{p}}}$ & Reference \\
\hline Silica Sand & $1200-1400$ & $400-600$ & 1.14 & $742-1175$ & {$[36,68-73]$} \\
\hline Hematite & $1565-1597$ & N/A & N/A & 650 & {$[36,74,75]$} \\
\hline $\begin{array}{l}\text { Silicon } \\
\text { Carbide }\end{array}$ & $2150-2250$ & $1470-1540$ & $90-110$ & $663-677$ & {$[68,71]$} \\
\hline AccucastID® & N/A & N/A & 0.7 & 1175 & {$[28,31,72]$} \\
\hline Carbo HSP® & N/A & N/A & 2 & 1275 & {$[23,28,31]$} \\
\hline Alumina & 2050 & $977-1030$ & $20-25.6$ & $790-800$ & {$[36,71,76]$} \\
\hline Zirconia & $2550-2700$ & $2150-2250$ & $1.7-2$ & $418-436$ & {$[71,77]$} \\
\hline CarboProp® & N/A & N/A & N/A & 1175 & {$[28,31,78]$} \\
\hline $\begin{array}{c}\text { Titanium } \\
\text { Dioxide }\end{array}$ & $1830-1850$ & $1570-1640$ & $4.8-9.2$ & $683-697$ & {$[71,76]$} \\
\hline $\begin{array}{l}\text { Magnesium } \\
\text { oxide }\end{array}$ & $2810-2860$ & $1980-2130$ & $30-60$ & $880-1030$ & {$[36,71,76,79]$} \\
\hline Manganosite & 1945 & N/A & N/A & $621-788$ & {$[75,80-82]$} \\
\hline Olivine & $1870-1950$ & $778-821$ & $8-10$ & $700-900$ & {$[71,83]$} \\
\hline Fly ash & $1270-1470$ & $873-973$ & $1.11-1.25$ & $813-867$ & [71] \\
\hline Graphite & $3530-3680$ & $2580-2690$ & $44.2-48.3$ & $852-941$ & {$[69,71,74]$} \\
\hline Basalt & $1410-1490$ & $500-850$ & $0,03-0,04$ & 840 & {$[68,71,84]$} \\
\hline
\end{tabular}

\section{Conclusions and future work}

The use of solid particle materials has big potential for developing a new generation of solar power towers. This new technology can enhance CSP thermal power plants to reduce electricity cost production as well as adding flexibility to the electric network, allowing a bigger renewable energies implementation. This technology will benefit highly irradiated regions, which happens to be the most expected regions to be developed during the following years increasing their energy needs over the world's average.

Incrementing current CSP service temperature has shown to have performance benefits when converting heat into electricity in the power block, by being able to use more efficient thermodynamic cycles or even use combined cycles using exhausted heat from topping cycle as input for one or more bottom cycles.

Current solid particle technology development has proven to be viable in the specific functional units balance (solar particle receiver, HEX, thermal storage). Nevertheless, further studies must be performed for conveyance and storage systems, since the most advanced research has been made on solar particle receivers and heat 
exchangers. Also, material considerations must be taken into the account, since the different parts of the power plant design expect different properties and parameters to be met by the particle media.

Future work should include:

a. Material selection according to each specific design (direct/indirect receiver, free falling or fluidized receiver, fluidized or packed bed heat exchanger, etc.), and needs to be optimized considering tradeoffs of particle properties in the major components. Therefore, there are properties that are in contradiction with others. For example, the mean size of the particles must be high to avoid sintering and agglomeration but must be low to facilitate heat transfer within the heat exchanger. Hence, the selected materials must present a compromise that fit all the requirements from the different parts of the system.

b. Thermal stress tests due to the high temperature itself in the long term and to the high number of charge/discharge thermal cycles expected during power plant lifetime (up to 11,000 is expected, that is one cycle per day during 30 year standard power plant lifetime). This behavior will influence particle media durability.

c. Mechanical stress tests due to possible attrition and erosion caused by/to the particle media and the plant built in materials.

d. Complete characterization of the best materials obtained from material selection, since most of the properties and parameters are expected to change because of the high temperature exposure, to the thermal cycles, and to the interaction with the plant functional units.

Finally, once best candidate materials have been completely studied, material combinations or material enhancement can be considered to level up the possible drawbacks of the best material selected.

\section{Acknowledgements}

The work is partially funded by the Spanish government ENE2015-64117-C5-2-R (MINECO/FEDER). The authors would like to thank the Catalan Government for the quality accreditation given to their research group DIOPMA (2017 SGR 118). The research leading to these results has received funding from Consejo Nacional de Ciencia y Tecnología CONACYT from México for the doctoral grant 546692.

\section{References}

[1] International Energy Agency. Deploying Renewables. Principles fo effective policies. France: 2008.

[2] International Energy Agency. Renewables 2017. Analysis and forecasts to 2022. 2017.

[3] International Energy Agency. World Energy Outlook 2018. 2018.

[4] OECD/IEA. World Energy Outlook. Paris: 2016.

[5] IRENA. Geothermal power: Technology brief. Abu Dhabi: 2017.

[6] IRENA. Renewable Energy Technologies: Cost Analysis Series. Hydropower. Abu Dhabi: 2012.

[7] IRENA. Renewable Energy Technologies: Cost Analysis Series. Biomass for Power Generation. Abu Dhabi: 2012.

[8] International Energy Agency. Technology Roadmap - Concentrating Solar Power 2010.

[9] Trieb F, Schillings C, O’Sullivan M, Pregger T, Hoyer-Klick C. Global Potential of Concentrating Solar Power. SolarPaces Conf. Berlin, Berlin: SolarPaces Conference; 2009.

[10] Steinmann W-D. Thermal energy storage systems for concentrating solar power (CSP) plants. Elsevier; 2012. doi:10.1533/9780857096173.2.362.

[11] Flamant G, Gauthier D, Benoit H, Sans J-L, Garcia R, Boissière B, et al. Dense suspension of solid particles as a new heat transfer fluid for concentrated solar thermal plants: On-sun proof of concept. Chem Eng Sci 2013;102:567-76. doi:10.1016/j.ces.2013.08.051. 
[12] Ma Z, Glatzmaier G, Mehos M. Fluidized Bed Technology for Concentrating Solar Power With Thermal Energy Storage. J Sol Energy Eng 2014;136:031014. doi:10.1115/1.4027262.

[13] Ho CK. High Temperature Falling Particle Receiver. Sunshot CSP R\&D FOA Ward Recip n.d. http://energy.sandia.gov/wp/wp-content/gallery/uploads

/8_Falling_Particle_Receiver_SunShot_FOA_poster_2012_v3.pdf (accessed January 10, 2015).

[14] Ma Z, Glatzmaier GC, Mehos M. Development of Solid Particle Thermal Energy Storage for Concentrating Solar Power Plants that Use Fluidized Bed Technology. Energy Procedia 2014;49:898-907. doi:10.1016/j.egypro.2014.03.097.

[15] Romero Manuel; González-Aguilar J. Solar thermal CSP technology. Wiley Interdiscip Rev Energy Environ 2014;3. doi:10.1002/wene.79.

[16] Ho CK, Iverson BD. Review of high-temperature central receiver designs for concentrating solar power. Renew Sustain Energy Rev 2014;29:835-46. doi:10.1016/j.rser.2013.08.099.

[17] Ho CK. High Temperature Falling Particle Receiver. SunShot CSP Progr Rev 20132013. http://energy.gov/sites/prod/files/2014/01/f7/csp_review_meeting_042413_ho.pdf.

[18] Ho CK. 6 - A new generation of solid particle and other high-performance receiver designs for concentrating solar thermal (CST) central tower systems. Adv. Conc. Sol. Therm. Res. Technol., 2017, p. 107-28. doi:10.1016/B978-0-08-100516-3.00006-X.

[19] Wu W, Amsbeck L, Buck R, Uhlig R, Ritz-Paal R. Proof of Concept Test of a Centrifugal Particle Receiver. Energy Procedia 2014;49:560-8. doi:10.1016/j.egypro.2014.03.060.

[20] Perez Lopez I, Benoit H, Gauthier D, Sans JL, Guillot E, Mazza G, et al. On-sun operation of a 150 $\mathrm{kW}$ th pilot solar receiver using dense particle suspension as heat transfer fluid. Sol Energy 2016;137:463-76. doi:10.1016/j.solener.2016.08.034.

[21] Broome ID, Miller F. Design and analysis of a multi-window aperture structure for a small particle solar receiver. 9th Annu. Int. Energy Convers. Eng. Conf. IECEC 2011, 2011.

[22] Bertocchi R, Karni J, Kribus A. Experimental evaluation of a non-isothermal high temperature solar particle receiver. Energy 2004;29:687-700. doi:10.1016/j.energy.2003.07.001.

[23] Ho CK, Khalsa SS, Siegel NP. Modeling On-Sun Tests of a Prototype Solid Particle Receiver for Concentrating Solar Power Processes and Storage. ASME 2009 3rd Int. Conf. Energy Sustain. Vol. 2, vol. 2, ASME; 2009, p. 543-50. doi:10.1115/ES2009-90035.

[24] Ma Z. NREL Particle Receiver Will Enable High-Temperature CSP. Natl Renew Energy Lab n.d. http://www.nrel.gov/docs/fy14osti/62504.pdf.

[25] Ma Z (National REL. Particle Receiver Integrated with Fluidized Bed. US Dep Energy 2012. http://energy.gov/sites/prod/files/2014/01/f7/55454.pdf (accessed January 26, 2015).

[26] Tan T, Chen Y. Review of study on solid particle solar receivers. Renew Sustain Energy Rev 2010;14:265-76. doi:10.1016/j.rser.2009.05.012.

[27] Miller F. Small-Particle Solar Receiver for High-Temperature Brayton Power Cycles. San Diego State Univ n.d. http://energy.gov/sites/prod/files/2014/01/f7/55459.pdf (accessed January 27, 2015).

[28] Ho C, Christian J, Gill D, Moya A, Jeter S, Abdel-Khalik S, et al. Technology Advancements for Next Generation Falling Particle Receivers. Energy Procedia 2014;49:398-407. doi:10.1016/j.egypro.2014.03.043.

[29] Albrecht KJ, Ho CK. Heat transfer models of moving packed-bed particle-to-SCO2 heat exchangers. ASME 2017 11th Int. Conf. Energy Sustain. ES 2017, collocated with ASME 2017 Power Conf. Jt. with ICOPE 2017, ASME 2017 15th Int. Conf. Fuel Cell Sci. Eng. Technol. ASME 201, 2017. doi:10.1115/ES2017-3377.

[30] Ho CK, Christian J, Yellowhair J, Jeter S, Golob M. Highlights of the High-Temperature Falling Particle 
Receiver Project: 2012 - 2016, n.d.

[31] Siegel N, Gross M, Ho C, Phan T, Yuan J. Physical Properties of Solid Particle Thermal Energy Storage Media for Concentrating Solar Power Applications. Energy Procedia 2014;49:1015-23. doi:10.1016/j.egypro.2014.03.109.

[32] Diver R SL. Serpentine Solar Particle Reciver. 2006.

[33] Wang F, Bai F, Wang T, Li Q, Wang Z. Experimental study of a single quartz tube solid particle air receiver. Sol Energy 2016;123:185-205. doi:10.1016/j.solener.2015.10.048.

[34] Jeter S, Sadowski D, Golob M, McKoy J, Stephens J, Lines B. Development of a novel thermal energy storage system using sand as the medium. 39th ASES Natl. Sol. Conf. 2010, Sol. 2010, vol. 2, 2010, p. 1279-85.

[35] El-Leathy A, Jeter S, Al-Ansary H, Abdel-Khalik S, Roop J, Golob M, et al. Thermal Performance Evaluation of Two Thermal Energy Storage Tank Design Concepts for Use with a Solid Particle Receiver-Based Solar Power Tower. Energies 2014;7:8201-16. doi:10.3390/en7128201.

[36] Schwaiger K, Haider M, Hämmerle M, Wünsch D, Obermaier M, Beck M, et al. sandTES - An Active Thermal Energy Storage System based on the Fluidization of Powders. Energy Procedia 2014;49:983-92. doi:10.1016/j.egypro.2014.03.106.

[37] Watkins MF, Gould RD. Dense granular flows as a new heat transfer fluid for concentrated solar power. ASME Int. Mech. Eng. Congr. Expo. Proc., vol. 8B-2015, 2015. doi:10.1115/IMECE2015-51069.

[38] Watkins MF, Gould RD. Heat transfer to vertical dense granular flows at high operating temperatures. ASME 2017 11th Int. Conf. Energy Sustain. ES 2017, collocated with ASME 2017 Power Conf. Jt. with ICOPE 2017, ASME 2017 15th Int. Conf. Fuel Cell Sci. Eng. Technol. ASME 201, 2017. doi:10.1115/ES2017-3272.

[39] Ashby MF. Materials Selection in Mechanical Design. Fourth Edi. Elsevier Ltd; 2011.

[40] Baumann T, Zunft S. Properties of granular materials as heat transfer and storage medium in CSP application. Sol Energy Mater Sol Cells 2015;143:38-47. doi:10.1016/j.solmat.2015.06.037.

[41] Siegel N, Kolb G. Design and on-sun testing of a solid particle receiver prototype. 2008 Proc. 2nd Int. Conf. Energy Sustain. ES 2008, vol. 2, 2009, p. 329-34.

[42] Perry RH, Green DW. Perry's Chemical Engineers Handbook. 7th Editio. McGraw-Hill; 1997.

[43] Lechner S, Merzsch M, Krautz HJ. Heat-transfer from horizontal tube bundles into fluidized beds with Geldart A lignite particles. Powder Technol 2014;253:14-21. doi:10.1016/j.powtec.2013.10.041.

[44] Geldart D. Types of gas fluidization. Powder Technol 1973;7:285-92. doi:10.1016/0032-5910(73)80037-3.

[45] Carter C. Barry; Norton M. Grant. Ceramic Materials. Science and Engineering. 2007.

[46] Wang C, Chen S-H. Factors influencing particle agglomeration during solid-state sintering. Acta Mech Sin 2012;28:711-9. doi:10.1007/s10409-012-0029-3.

[47] Carter CB, Norton MG. Sintering and Grain Growth. Ceram. Mater. Sci. Eng., 2007, p. 427-43.

[48] Fernández P, Miller FJ. Performance analysis and preliminary design optimization of a Small Particle Heat Exchange Receiver for solar tower power plants. Sol Energy 2015;112:458-68. doi:10.1016/j.solener.2014.11.012.

[49] Norena LE, Wang J-A. Advanced Catalytic Materials - Photocatalysis and Other Current Trends. InTech; 2016. doi:10.5772/60491.

[50] Modest MF, editor. Radiative Heat Transfer. Third Edit. Boston: Academic Press; 2013.

[51] Molerus O, Wirth K-E. Heat Transfer in Fluidized Beds. Erlangen-Nürnberg: Springer-science+business 
media; 1997.

[52] Modest MF. Fundamentals of Thermal Radiation. Radiat. Heat Transf. Third Edit, Boston: Academic Press; 2013, p. 1-28.

[53] Modest MF. Radiation Combined with Conduction and Convection. Radiat. Heat Transf. Third Edit, Boston: Academic Press; 2013, p. 724-78.

[54] Modest MF. Radiative Properties of Particulate Media. Radiat. Heat Transf. Third Edit, Boston: Academic Press; 2013, p. 387-439.

[55] Ebbing DD, Gammon SD. General Chemistry. 9th editio. Houghton Mifflin Company; 2009.

[56] Papendick RI, Campbell GS. Theory and measurement of water potential [in soil, organic materials, plants, seeds, and microorganisms] 1981.

[57] Picandet V. Bulk density and compressibility. RILEM State-of-the-Art Reports 2017;23:111-24. doi:10.1007/978-94-024-1031-0_5.

[58] Schlipf D, Schicktanz P, Maier H, Schneider G. Using Sand and other Small Grained Materials as Heat Storage Medium in a Packed Bed HTTESS. Energy Procedia, vol. 69, 2015, p. 1029-38. doi:10.1016/j.egypro.2015.03.202.

[59] Diago M, Iniesta AC, Soum-Glaude A, Calvet N. Characterization of desert sand to be used as a hightemperature thermal energy storage medium in particle solar receiver technology. Appl Energy 2018;216:402-13. doi:10.1016/j.apenergy.2018.02.106.

[60] Lienhard, John H IV; Lienhard JH V. A Heat Transfer Textbook. Third edit. Cambridge, MA: Phlogiston Press; 2003.

[61] OpenStax. Collegue Physics, Conduction. Rice Univ 2015. https://cnx.org/contents /Ax2o07U1@9.4:p77aQy86@7/Conduction (accessed November 15, 2017).

[62] Rupasinghe M, Ngo T. Nanoengineering Concrete for Sustainable Built Environment: A Review 2018.

[63] Karlsson O, Schade BEH. Particle Analysis. 2013. doi:10.1002/9781118638521.ch9.

[64] Horiba Scientific. A Guidebook to Particle Size Analysis n.d. https://www.horiba.com/fileadmin /uploads/Scientific/eMag/PSA/Guidebook/ (accessed October 6, 2017).

[65] Ge Z, Li Y, Li D, Sun Z, Jin Y, Liu C, et al. Thermal energy storage: Challenges and the role of particle technology. Particuology 2014;15:2-8. doi:10.1016/j.partic.2014.03.003.

[66] Bullard JE. Examining Particle Shape. vol. 14. 2013. doi:10.1016/B978-0-12-374739-6.00386-9.

[67] Krumbein WC, Sloss LL. Stratigraphy and sedimentation. San Francisco: W.H. Freeman; 1956.

[68] Engineering ToolBox. Emissivity Coefficients Materials 2003. https://www.engineeringtoolbox.com /emissivity-coefficients-d_447.html (accessed June 21, 2018).

[69] ThermoWorks. Emissivity Table 2018. https://www.thermoworks.com/emissivity_table (accessed June $16,2018)$.

[70] Engineering ToolBox. Absorbed Solar Radiation 2009. https://www.engineeringtoolbox.com/solarradiation-absorbed-materials-d_1568.html (accessed June 14, 2018).

[71] Granta Design Limited. CES Selector 20182018.

[72] Carboceramics. CarboAccucast Low and intermediate density ceramic casting media. Technical data sheet. 2014.

[73] Carboceramics. CarboHSP High-density sintered bauxte proppant. Datasheet. 2015.

[74] Henninger JH. Solar Absorptance and Thermal Emittance of Some Common Spacecraft Thermal 
Control Coatings. 1984.

[75] John W. Anthony, Bideaux RA, Bladh KW, Nichols MC. Handbook of Mineralogy. Mineral Soc Am 2005. http://www.handbookofmineralogy.org (accessed June 26, 2018).

[76] Martínez I. Thermo-Optical Properties. Univ Politécnica Madrid 2018. http://webserver.dmt.upm.es / isidoro/dat1/Thermooptical.pdf (accessed June 26, 2018).

[77] Omega Tm. Emissivity of Common Materials. Tech Ref Ser n.d. https://www.omega.com/literature /transactions/volume1/emissivityb.html\#_top (accessed June 30, 2018).

[78] World Oil. Proppant Tables 20142014.

[79] AZO Materials. Magnesia - Magnesium Oxide (MgO) Properties \& Applications n.d. https://www.azom.com/properties.aspx?ArticleID=54 (accessed July 2, 2018).

[80] Fritsch S, Navrotsky A. Thermodynamic Property of Manganese Oxides. J Am Ceram Soc 2005;79:1761-8.

[81] H. Reidies A. Manganese Compounds 2000.

[82] Hemingway BS, Robie RA. Thermodynamic properties of zeolites: low-temperature heat capacities and thermodynamic functions for phillipsite and clinoptilolite. Estimates of the thermochemical properties of zeolitic water at low temperature. Am Mineral 1984;69:692.

[83] Barthelmy D. Olivi[1] Barthelmy D. Olivine Mineral Data. Mineral Database 2012. http://webmineral.com/data/Olivine.shtml (accessed June 22, 2018).ne Mineral Data. Mineral Database 2012. http://webmineral.com/data/Olivine.shtml (accessed June 22, 2018).

[84] Engineering ToolBox. Specific Heat of Solids 2003. https://www.engineeringtoolbox.com/specific-heatsolids-d_154.html (accessed July 2, 2018). 